\title{
Fas ligand gene expression is directly regulated by stress-inducible heat shock transcription factor-1
}

\author{
L Bouchier-Hayes ${ }^{1}$, S McBride ${ }^{2,4}$, CM van Geelen ${ }^{1,5}$, S Nance ${ }^{1}$, LK Lewis ${ }^{3}$, MJ Pinkoski ${ }^{3}$ and HM Beere ${ }^{\star, 1}$
}

Heat shock transcription factor-1 (HSF-1) is the primary stress responsive transcription factor that regulates expression of heat shock proteins (Hsps) in response to elevated temperature. We show that the transcriptional activity of HSF-1 can also directly mediate hyperthermia-induced Fas ligand (FasL) expression in activated T cells. We identify a conserved region within the human FasL promoter spanning from -276 to -236 upstream of the translational start site that contains two $15 \mathrm{bp}$ non-identical adjacent HSF-1-binding sites or heat shock elements (HSEs) separated by 11 bp. Both the distal HSE (HSE1) (extending from -276 to -262 ) and the proximal HSE (HSE2) (spanning from -250 to -236) consist of two perfect and one imperfect nGAAn pentamers. We show the direct binding of HSF-1 to these elements and that mutation of these sites abrogates the ability of HSF-1 to bind and drive promoter activity. HSF-1 associates with these elements in a cooperative manner to mediate optimal promoter activity. We propose that the ability of HSF-1 to mediate stress-inducible expression of FasL extends its classical function as a regulator of Hsps to encompass a function for this transcription factor in the regulation of immune function and homeostasis. Cell Death and Differentiation (2010) 17, 1034-1046; doi:10.1038/cdd.2010.4; published online 12 February 2010

Mammalian heat shock transcription factor-1 (HSF-1) exists constitutively as a non-DNA-binding cytosolic monomer that when activated by heat stress, forms active homotrimers that translocate to the nucleus and associate with consensusbinding sites within the promoters of its target genes. ${ }^{1-3}$ These heat shock elements (HSEs) are characterized by concatenation of a minimum of three inverted pentameric repeats, nGAAn, to form the 15 -bp idealized HSE motif nGAAnnTTCnnGAAn. ${ }^{4,5}$ HSF-1 binding to these elements is cooperative at two levels - both within the subunits of the HSF-1 trimer and between multimers such that the binding of HSF-1 to one binding site facilitates its binding to an adjacent site. ${ }^{5-7}$ Therefore, the overall composition of HSEs, including the number of binding sites, fidelity to consensus, nature of the flanking sequence, orientation and spacing of consensus pentamers governs the affinity of HSF-1 for these binding regions and the relative inducibility of the target gene.

Fever is a highly conserved physiological response that is mediated largely by the pyrogenic activities of TNF- $\alpha, \mathrm{IL}-1 \beta$ and IL- $6 .{ }^{8}$ The precise physiological function of the fever response is unclear, although it seems to enhance the capacity of the host defense system as evidenced by hyperthermiainduced enhancement of antigen processing, ${ }^{9}$ dendritic cell maturation $^{10}$ and pathogen clearance. ${ }^{11}$ The associated elevation in body temperature during infection has also been shown to impact on $\mathrm{T}$ cell proliferative capacity ${ }^{12}$ and significantly alter the secretion of a number of cytokines including TNF- $\alpha$, IL-1 $\beta$ and IL- $6 .{ }^{13}$ Interestingly, each of these cytokines is subject to transcriptional regulation by HSF-1 $1^{14-16}$ raising the interesting possibility that the elevation in temperature associated with infection engages HSF-1 activity to help co-ordinate an appropriate immune response. Of note, the increase in temperature associated with fever $\left(39-40^{\circ} \mathrm{C}\right)$ is sufficient to activate endogenous HSF-1 in primary T cells, but not other tissue types. ${ }^{17}$

The clonal expansion of an activated $\mathrm{T}$ cell population is halted by the engagement of apoptotic cell death to restore normal cell number and to maintain immune homeostasis. This phenomenon, known as activation-induced cell death (AICD), is dependent on the transcriptional upregulation of Fas ligand (FasL) and interaction with its receptor, Fas, to activate caspase-8. ${ }^{18-20}$ The transcriptional regulation of FasL to alter cellular sensitivity to Fas-mediated apoptosis is also observed after stress imposed by DNA damage. ${ }^{21}$ One study also implicated hyperthermic stress in the transcriptional regulation of FasL in activated $T$ cells to mediate enhanced cytotoxicity of Fas-bearing target cells. ${ }^{22}$ Elevated temperature can also impact on the Fas/FasL signaling pathway through its suppression of FLIP levels ${ }^{23}$ and expression of a dominant active form of HSF-1 has been reported to elevate sensitivity to Fas-mediated killing, ${ }^{24}$ but whether this reflects a simultaneous regulation of FasL levels is unclear. Furthermore, gld mice, lacking functional FasL exhibit a decreased sensitivity to heat shock-induced death. ${ }^{25}$

\footnotetext{
${ }^{1}$ Department of Immunology, St Jude Children's Research Hospital, Memphis, TN, USA; ${ }^{2}$ La Jolla Institute for Allergy and Immunology, La Jolla, CA, USA; ${ }^{3}$ MRC Toxicology Unit, University of Leicester, Leicester, UK

*Corresponding author: HM Beere, Department of Immunology, St Jude Children's Research Hospital, 262 Danny Thomas Place, Memphis, TN 38105-3678, USA. Tel: + 1901595 4975; Fax: + 1901595 3107; E-mail: helen.beere@ stjude.org

${ }^{4}$ Current address: CalTech, Pasadena, CA, USA

${ }^{5}$ Aimm Therapeutics, Amsterdam, The Netherlands

Keywords: HSF-1; apoptosis; FasL

Abbreviations: HSF-1, heat shock transcription factor-1; Hsps, heat shock proteins; FasL, Fas ligand; HSEs, heat shock elements; AICD, activation-induced cell death Received 07.7.09; revised 15.12.09; accepted 22.12.09; Edited by SJ Martin; published online 12.2.10
} 
Collectively, these studies implicate elevated temperature in the regulation of the Fas/FasL signaling pathway. It is, therefore, interesting to speculate whether this reflects a direct regulatory function for HSF-1. We sought to test this possibility by examining whether HSF-1 is able to modulate the expression of FasL in activated $T$ cells. We were able to define FasL as a novel target for the transcriptional activity of HSF-1 and characterize two consensus-binding sites or HSEs housed within the proximal region of the FasL promoter. We show that these two adjacent sites are independently able to bind HSF-1 and that they function in a cooperative manner to ensure optimal FasL promoter activity. These data present FasL as a novel target of HSF-1 transactivation activity and extend the classical function of this stress inducible transcription factor to include a fundamental function in the maintenance and restoration of immune homeostasis.

\section{Results}

Earlier studies showed a function for Fas/FasL interactions in heat shock-induced death ${ }^{25}$ and an induction of FasL in T cells following hyperthermic shock. ${ }^{22}$ However, whether this reflects a direct transcriptional function for HSF-1 at the level of the FasL promoter remains unknown.
Heat shock potentiates the expression of FasL in activated $\mathbf{T}$ cells. To determine whether heat stress could induce FasL, Jurkat $T$ cells were activated by PMA and ionomycin or plate bound anti-CD3 with or without soluble anti-CD28 before exposure to heat stress. PMA/ionomycin (Figure 1a) or T cell receptor (TCR)-induced expression of FasL (Figure 1b) was potentiated in cells exposed to heat stress compared with heat stress alone. Similar observations were made using activated primary human peripheral blood lymphocytes (PBLs) (Figure 1c). Importantly, heat-induced FasL expression seemed specific as pre-activation with either PMA and ionomycin (Figure 1d) or anti-CD3 (Figure 1e) failed to synergize with heat to further induce expression of heat shock protein 70 (Hsp70). In addition, neither the expression of TNF nor TRAIL was further elevated by heat in activated Jurkat $T$ cells, further confirming the specificity of the effects we observed (Figure 2).

Heat shock induces the expression of functional FasL in activated $T$ cells to induce cell death in Fas $^{+}$target cells. To assess whether the induction of FasL gene expression could be detected as elevated expression of functional FasL protein, we evaluated cell surface expression

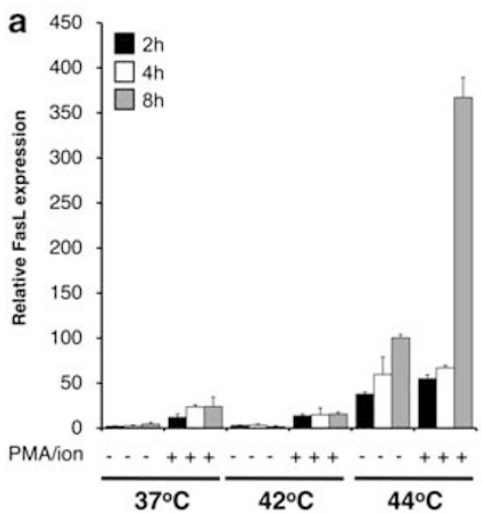

b
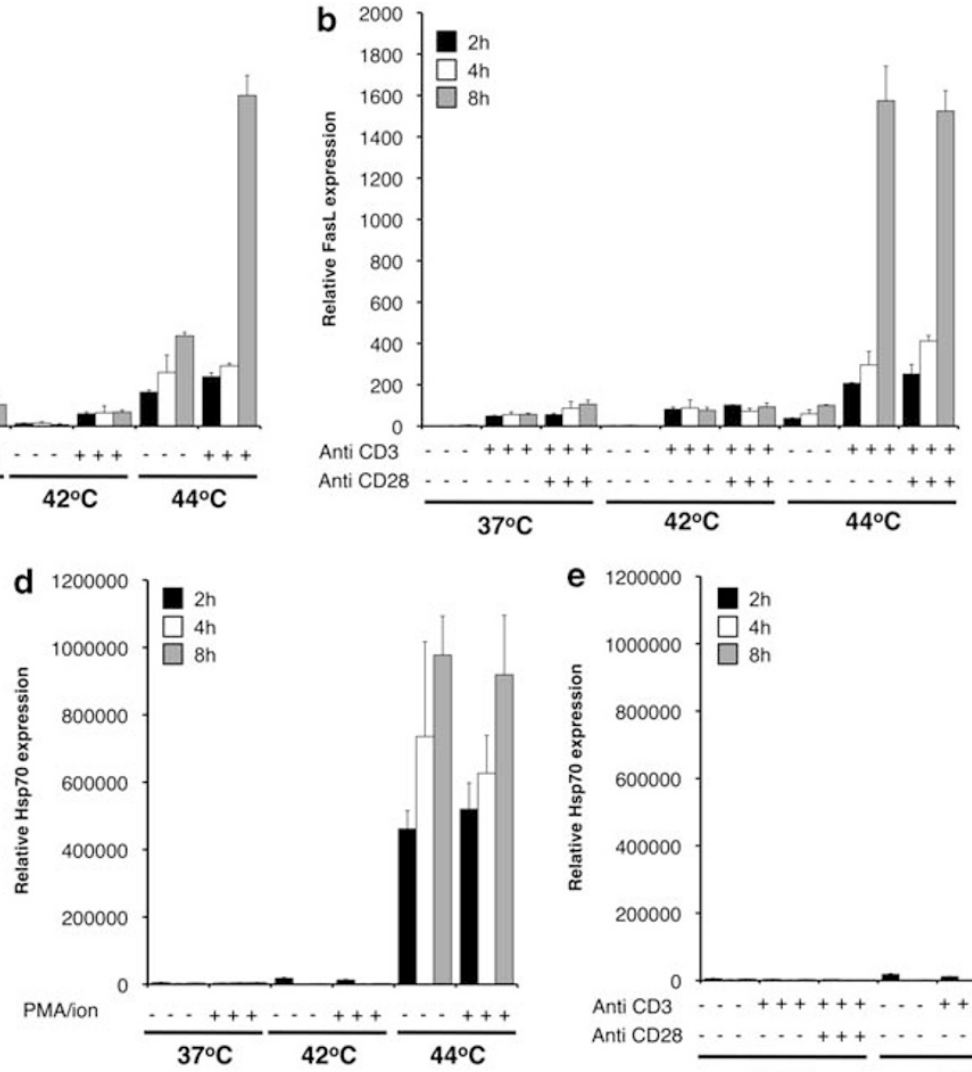

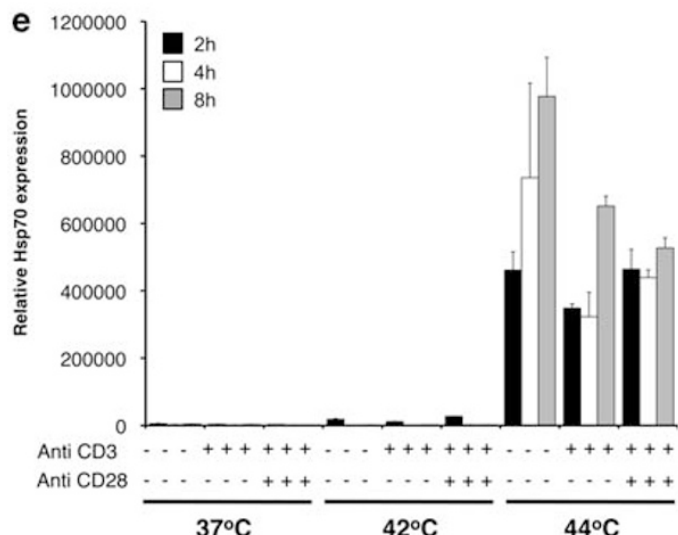

C

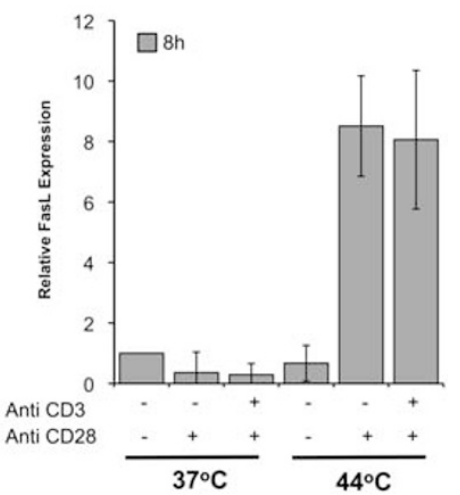

Figure 1 Heat shock potentiates FasL expression in activated T cells. Jurkat T cells or primary human PBLs were activated overnight by treatment with PMA (50 $\mathrm{nM}$ ) and ionomycin $(1 \mu \mathrm{g} / \mathrm{ml})$ or plate bound anti-CD3 $(1 \mu \mathrm{g} / \mathrm{ml})$ plus or minus anti-CD28 $(2 \mu \mathrm{g} / \mathrm{ml})$ before exposure to heat shock $\left(42-44^{\circ} \mathrm{C}\right.$ for $\left.60 \mathrm{~min}\right)$. This was followed by a period of recovery for up to $8 \mathrm{~h}$ at $37^{\circ} \mathrm{C}$ as indicated. RNA was prepared at the indicated times and used for reverse transcription and qPCR to determine the relative expression levels of FasL in Jurkat T cells $(\mathbf{a}, \mathbf{b})$ or human PBLs (c) and Hsp70 in Jurkat T cells (d, e). Data shown is normalized to $18 \mathrm{~S}$ and is representative of five independent experiments (Jurkat T cells) or the average ( + / -S.D.) of three independent primary PBL samples 
a

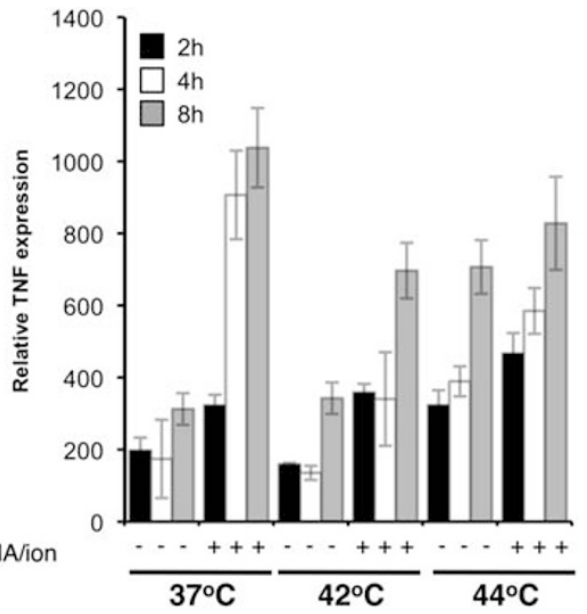

C

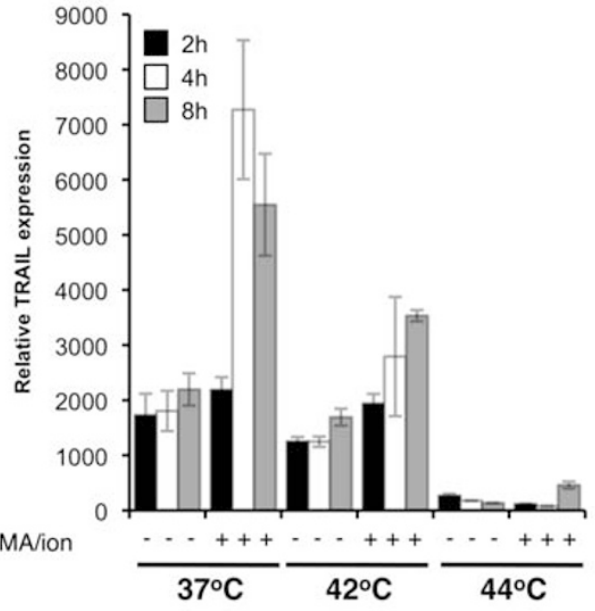

b

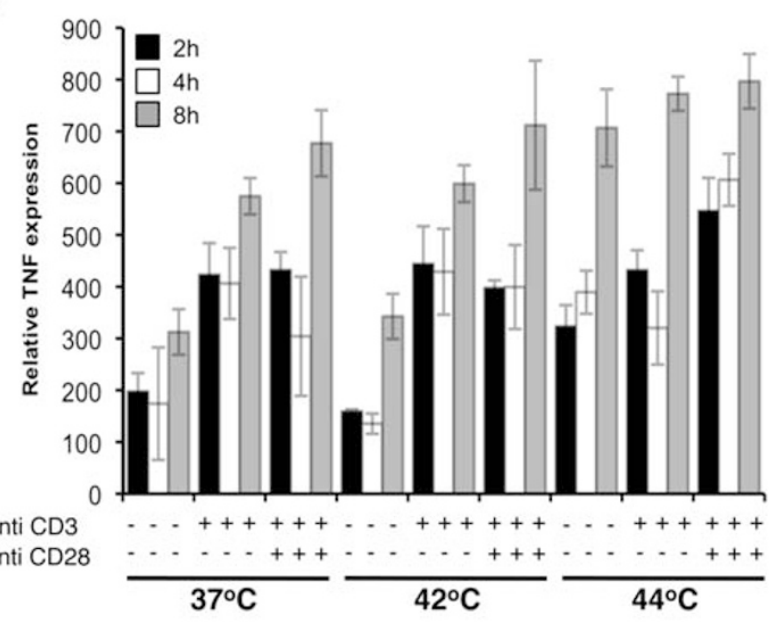

d

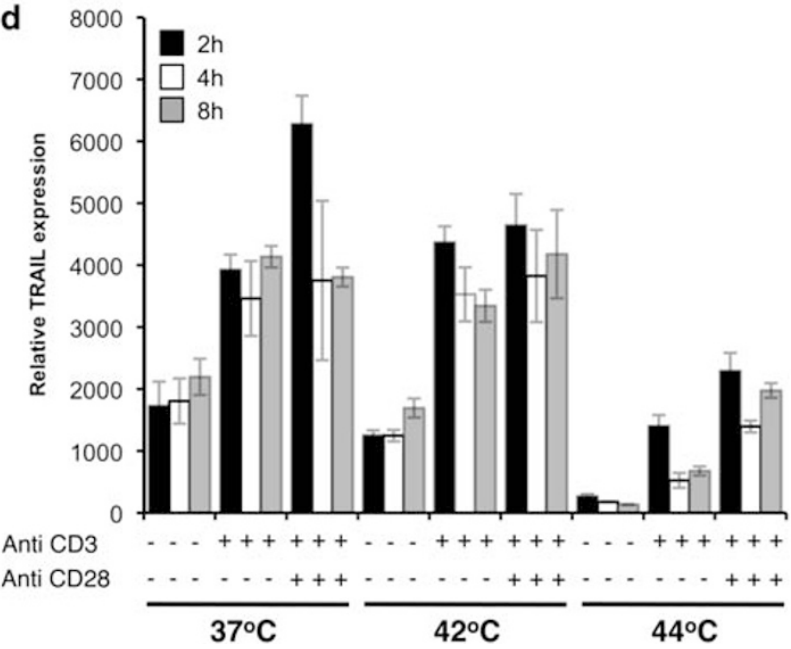

Figure 2 Heat shock does not potentiate TRAIL or TNF expression in activated T cells. Jurkat T cells were activated by overnight treatment with PMA (50 nM) and ionomycin $(1 \mu \mathrm{g} / \mathrm{ml})$ or plate bound anti-CD3 $(1 \mu \mathrm{g} / \mathrm{ml})$ plus or minus soluble anti-CD28 $(2 \mu \mathrm{g} / \mathrm{ml})$. Cells were then exposed to elevated temperature $\left(42-44{ }^{\circ} \mathrm{C}\right.$ for $\left.60 \mathrm{~min}\right)$ and allowed to recover for up to $8 \mathrm{~h}$ at $37^{\circ} \mathrm{C}$ as indicated. RNA was then prepared and real-time PCR used to determine the levels of TNF (a, b) or TRAIL (c, d) gene expression. Data shown is normalized to $18 \mathrm{~S}$ and is representative of five independent experiments

of FasL in activated T cells exposed to heat shock as well as their ability to induce cell death of Fas ${ }^{+}$target cells. Using antibody-specific staining, we observed a significant increase in both the percentage of Jurkat $T$ cells expressing FasL and the amount of FasL staining/per cell (as determined by mean fluorescence intensity) after exposure to elevated temperature $\left(44^{\circ} \mathrm{C}\right)$ that was further increased by treatment with anti-CD3/CD28 (Figure 3a). Heat-induced expression of FasL in activated Jurkat $T$ cells was also reflected by their ability to induce significantly more cell death of Fas ${ }^{+}$L1210 target cells (compare bars denoted by *) as compared with L1210 control cells (compare bars denoted by \#) (Figure 3b). Although activated Jurkat $\mathrm{T}$ cells were also able to induce some cell death in the target L1210 target population independently of elevated temperature (marked by dotted line), the percentage of cell death was unchanged in the L1210-Fas cell line, suggesting that it was mediated in an FasL-independent manner.

Collectively, the data shown in Figures 1-3 indicate that heat and TCR activation cooperate to optimally and specifi- cally induce FasL expression. We hypothesized that this may be mediated through the direct engagement of HSF-1 activity and conducted a series of experiments to test this.

HSF-1 drives expression of the FasL promoter. To examine whether HSF-1 could drive expression of the FasL promoter, we transfected Jurkat $\mathrm{T}$ cells with luciferase reporter constructs containing $1.2,{ }^{21} 0.8^{21}$ or $0.486 \mathrm{~kb}^{26}$ of the human FasL promoter with or without a plasmid expressing constitutively active HSF-1. ${ }^{1,24} \mathrm{HSF}-1$ induced the activity of each of the FasL promoter constructs (Figure $4 a-c)$ in a dose-dependent manner (Figure 4d). Moreover, HSF-1 greatly enhanced PMA/ionomycin-induced activation of the $1.2 \mathrm{~kb}$ FasL promoter (Figure 4e), consistent with our observation that hyperthermic shock of $T$ cells activated by PMA and ionomycin pretreatment leads to the enhanced expression of endogenous FasL (Figure 1a). Collectively, these data indicated that the proximal $0.5 \mathrm{~kb}$ of the FasL promoter contained one or more HSF-1 responsive elements that are important for heat-induced FasL transcription. 


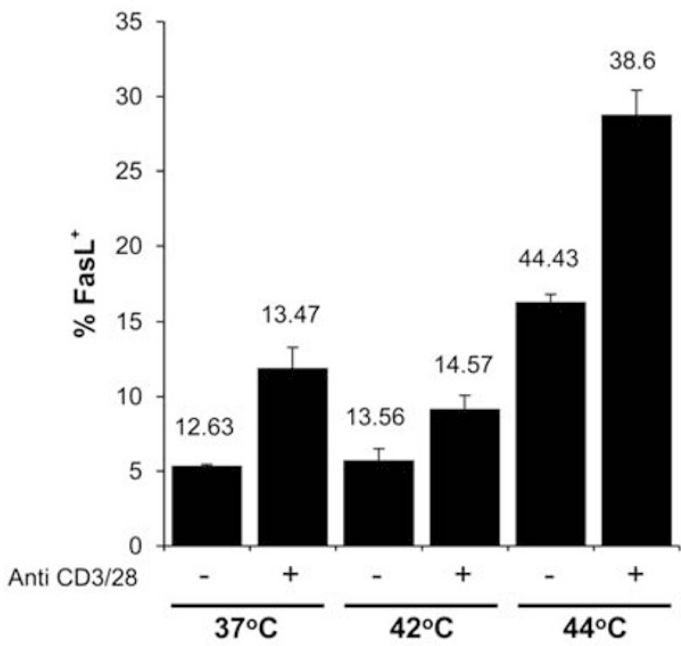

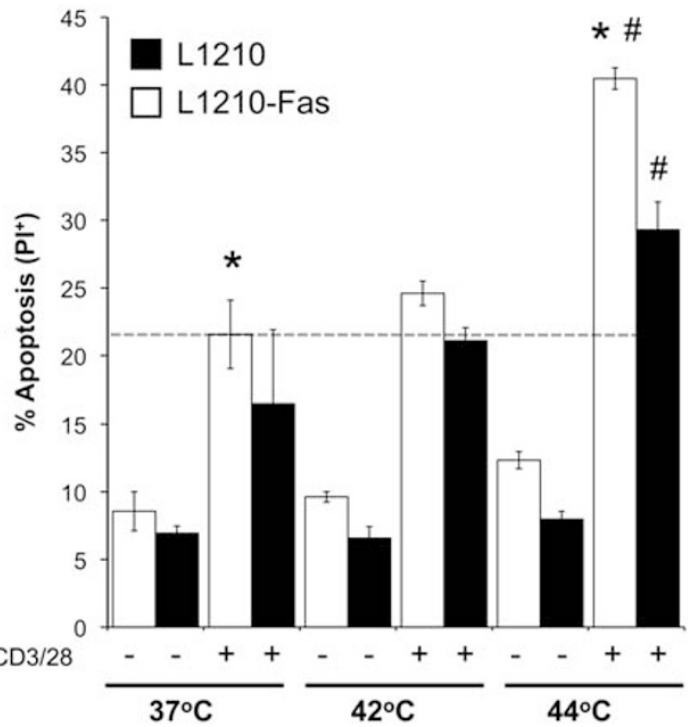

Figure 3 Heat shock potentiates FasL expression in activated T cells to kill Fas ${ }^{+}$target cells. Jurkat T cells were activated or not (as indicated) with plate bound anti-CD3 and soluble anti-CD28 overnight before heat shock at $42-44^{\circ} \mathrm{C}$ and recovery for $16 \mathrm{~h}$ in the presence of 1,10 phenanthroline (1.5 $\left.\mu \mathrm{M}\right)$. Cells were then stained with biotinlabeled anti-FasL (NOK1) (or IgG control antibody) and streptavidin antibodies - antibody-specific staining was detected through FACS analysis. Secondary antibody alone also served as a control. Data shown indicates the $\% \mathrm{Fas}^{+}$population and is representative of three independent experiments. Mean fluorescence intensity (MFI) values are also shown (a). Activated Jurkat T cells were exposed to heat shock before overnight recovery and incubation with PH67GL-labeled L1210 (black bars) or L1210-Fas (white bars) at a 10: 1 effector : target ratio. After an additional overnight incubation, cell death was assessed by PI staining and FACS analysis. Comparison of the bars labeled with * indicate Fas-specific killing induced by heat and TCR activation (compared with TCR activation alone) that is abrogated in L1210 control cells (compare bars labeled with \#). Data shown are representative of three independent experiments $(\mathbf{b})$

Human FasL promoter contains HSEs that bind HSF-1. Visual analysis of the proximal $0.5 \mathrm{~kb}$ region of the FasL promoter revealed two likely HSEs (HSE1 (-276 to -262) and HSE2 (-250 to -236)). HSF-1-binding parameters can tolerate a degree of flexibility from the consensus sequence, nGAAn, providing some key elements are maintained - these include a minimum of three inversely orientated pentamers, each of which maintain the ' $G$ ' at position 2. HSE1 contains three pentameric-binding motifs of which sites 1 and 2 preserve consensus, whereas the third, although imperfect, retains the essential $G$ at position 2 . HSE2 also harbors two perfect pentamers, numbers 4 and 6 , and an imperfect binding motif $5^{\prime}$-nGAGn-3' at position 5 (Figure 5a).

Using recombinant human HSF-1, which spontaneously forms trimers in solution at concentrations in excess of $40 \mathrm{ng} / \mathrm{ml}$ that are able to associate with $\mathrm{DNA}^{3}$ and an oligonucleotide encompassing the two putative HSEs from the FasL promoter or, for comparison, a 35-bp stretch from the human Hsp70 promoter, ${ }^{27}$ we evaluated whether HSF-1 could bind to the FasL promoter. HSF-1 binding (>150 ng ( $25 \mathrm{nM})$ ) to the oligonucleotides from both the FasL (Figure $5 \mathrm{~b}$, lanes 6-15) and the Hsp70 promoters seemed similar (Figure 5c, lanes 6-15).

HSEs in the FasL promoter compete HSF-1 binding from the Hsp70 promoter. To determine whether endogenously activated HSF-1 can directly interact with the proposed HSEs, we performed a series of electromobility shift analyses (EMSAs), supershift analyses and competition studies using oligonucleotides from the Hsp70 promoter containing previously defined $\mathrm{HSEs}^{27}$ and regions from the FasL promoter containing one or both the putative HSEs.

Nuclear extract isolated from untreated or heat-shocked Jurkat $T$ cells was incubated with an oligonucleotide from the proximal region of the Hsp70 promoter (Figure 6). As predicted, we observed a retardation of oligonucleotide mobility when incubated with extracts from heat-shocked cells (lane 3 in each of Figure $6 a-c$ ), but not unstimulated control cells (lane 2 in each of Figure $6 a-c$ ). This activity was supershifted with an anti-HSF-1 (lanes 4 and 5 in each of Figure $6 a-c$ ), but not an anti-HSF-2 antibody (lanes 6 and 7 in each of Figure $6 \mathrm{a}-\mathrm{c}$ ). The heat-inducible-binding activity was competed by unlabeled oligonucleotides containing both HSE1 and HSE2 from the FasL promoter (Figure 6a, lanes 8-11), but not by an oligonucleotide containing mutations in the essential bases in each of the six pentameric repeats (Figure 6a, lanes 12-15). Oligonucleotides containing either the HSE1 or HSE2 also competed for HSF-1-binding activity from the Hsp70 promoter region (Figure $6 \mathrm{~b}$ and $\mathrm{c}$, lanes 8-11), whereas mutant (mt) oligonucleotides containing mutations at the key residues required for HSF-1 binding did not (Figure 6b and c, lanes 12-15).

Heat shock-induced binding activity to putative HSEs in the FasL promoter. To determine whether nuclear extracts isolated from heat-shocked cells contained an activity able to directly associate with specific regions within the FasL promoter, we conducted EMSAs using radiolabeled oligonucleotides containing both or each of the putative HSEs. A binding activity in nuclear extracts isolated from heat-shocked cells, but not unstimulated Jurkat cells, bound 


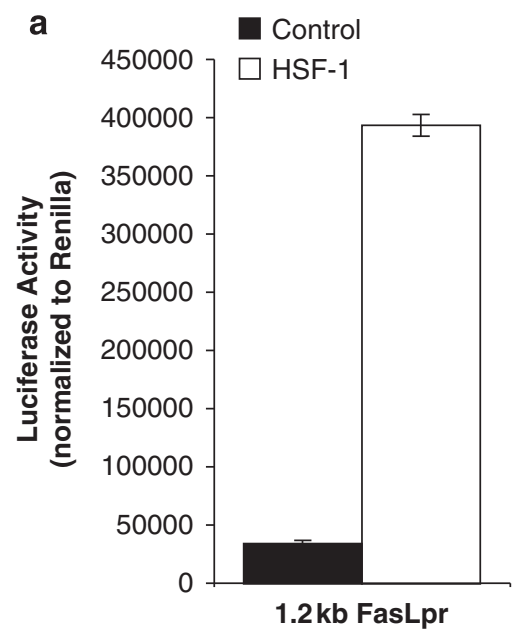

d

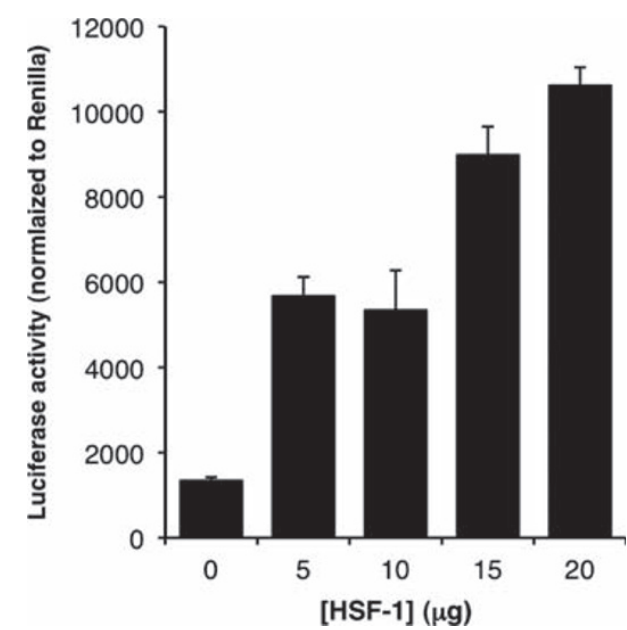

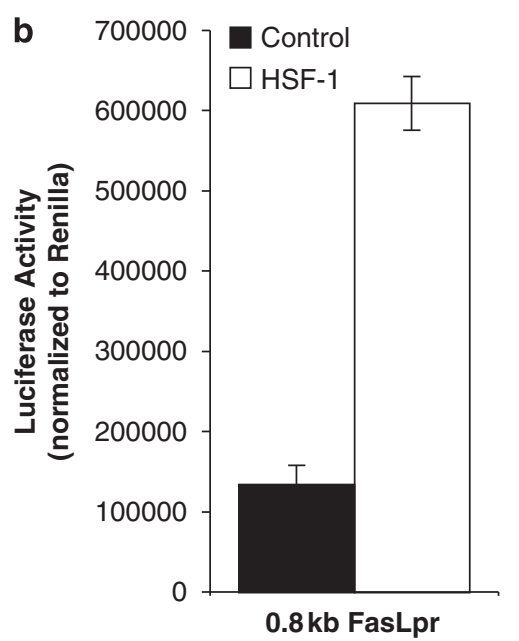
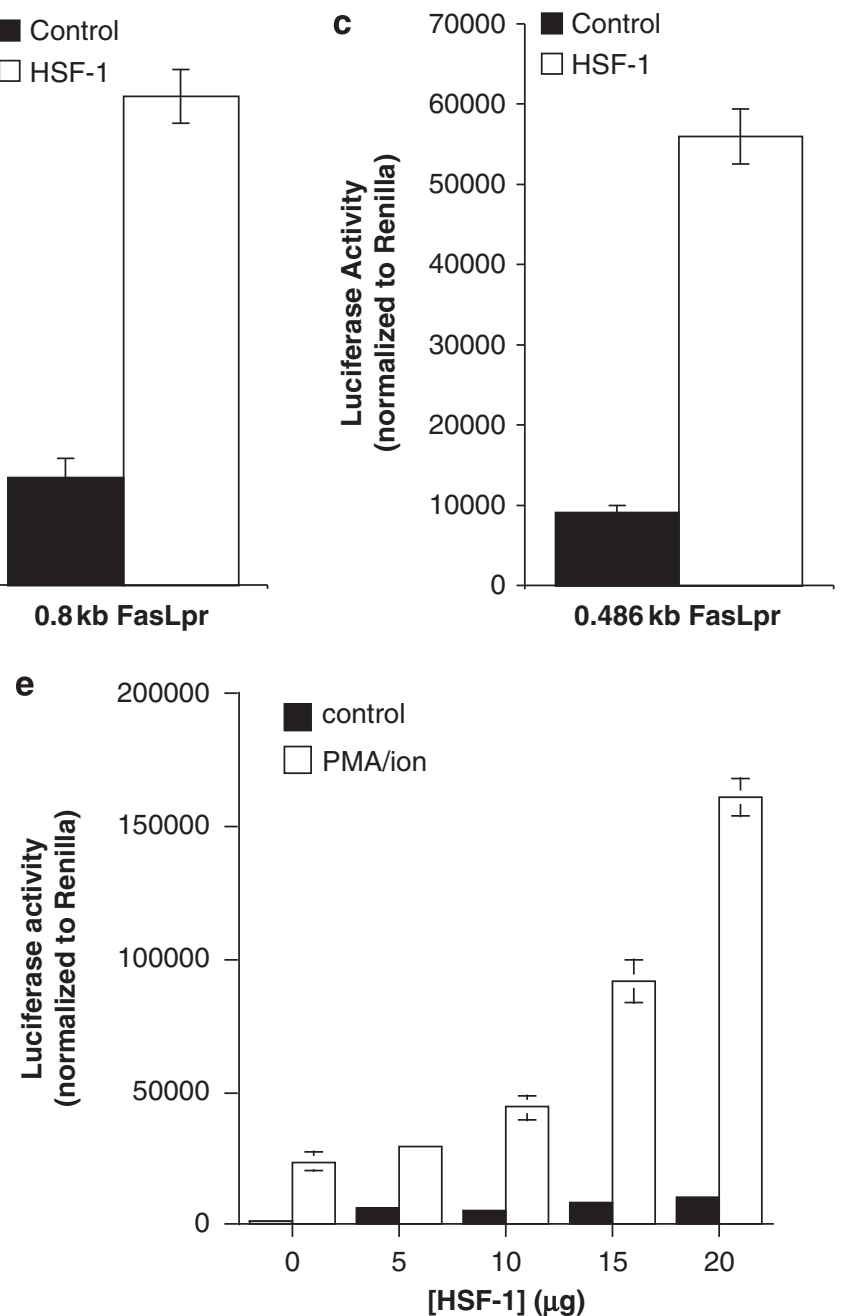

Figure 4 HSF-1 can drive FasL promoter activity. Jurkat T cells were cotransfected with a luciferase reporter construct containing 1.2 (a), (d) and (e), 0.8 (b) or $0.486 \mathrm{~kb}$ regions from the $\mathrm{hFasL}$ promoter (c) plus increasing amounts of HSF-1 plasmid. After $24 \mathrm{~h}$, cells were either harvested and Firefly luciferase activity measured and normalized to an internal Renilla luciferase standard (a-d) or treated with PMA $(50 \mathrm{nM})$ and ionomycin $(1 \mu \mathrm{g} / \mathrm{ml})$ and incubated for an additional $24 \mathrm{~h}$. Cells were then collected and Firefly luciferase activity measured and normalized to an internal Renilla luciferase standard. Data shows the average of triplicates from one representative experiment performed at least six times

strongly to the oligonucleotide containing both the HSE1 and HSE2 from the FasL promoter (Figure 7a, compare lanes 2 and 3) and was supershifted by an anti-HSF-1, but not an anti-HSF-2 antibody (Figure 7, lanes 4 and 5, respectively). However, the mt counterpart of the $2 \times$ HSE oligonucleotide, containing mutations in each of the key bases, was not bound by nuclear extracts isolated from heat-shocked cells (Figure 7a, lanes 8-10).

HSF-1 bound to oligonucleotides containing either HSE1 or HSE2 as observed by the retardation in nuclear extracts isolated from heat-shocked cells (lane 3 in both Figure $8 a$ and $b$ ), but not unstimulated cells (lane 2 in both Figure $8 \mathrm{a}$ and $\mathrm{b}$ ), and by supershift using an anti-HSF-1 (lane 4 in both Figure 8a and b), but not anti-HSF-2 antibody (lane 5 in both Figure $8 a$ and $b$ ). Mutation of each of the three pentamers in HSE1 or those in HSE2 abolished binding of HSF-1 (lanes 6-10 in both Figure 8a and b, respectively) to the individual HSEs. It seemed that HSE1 displayed a more efficient binding or greater affinity for HSF-1 than HSE2 (compare lanes 1-5 with lanes 10-15 in both Figure $8 a$ and $b$ ).

To determine whether there was any cooperative binding between the two HSEs in the FasL promoter, we performed EMSA analysis comparing HSF-1 binding to the wild-type (wt) oligonucleotide harboring both HSEs to oligonulceotides containing mutations at each of the three key residues within either HSE1 or HSE2. Surprisingly, we observed that mutation of each of the key residues within HSE2 of the $2 \times$ HSE probe did not seem to significantly affect HSF-1 binding (Figure 7b, compare lanes 1-5 with 11-15). However, when using an oligonucleotide containing mutations only within the HSE1, we observed an almost complete abolition of HSF-1-binding activity (Figure $7 \mathrm{~b}$, compare lanes $1-5$ with 6-10). These data strongly suggest that while both HSE1 and HSE2 can independently interact with HSF-1, mutation of HSE1 in the context of the extended binding region severely compromises 


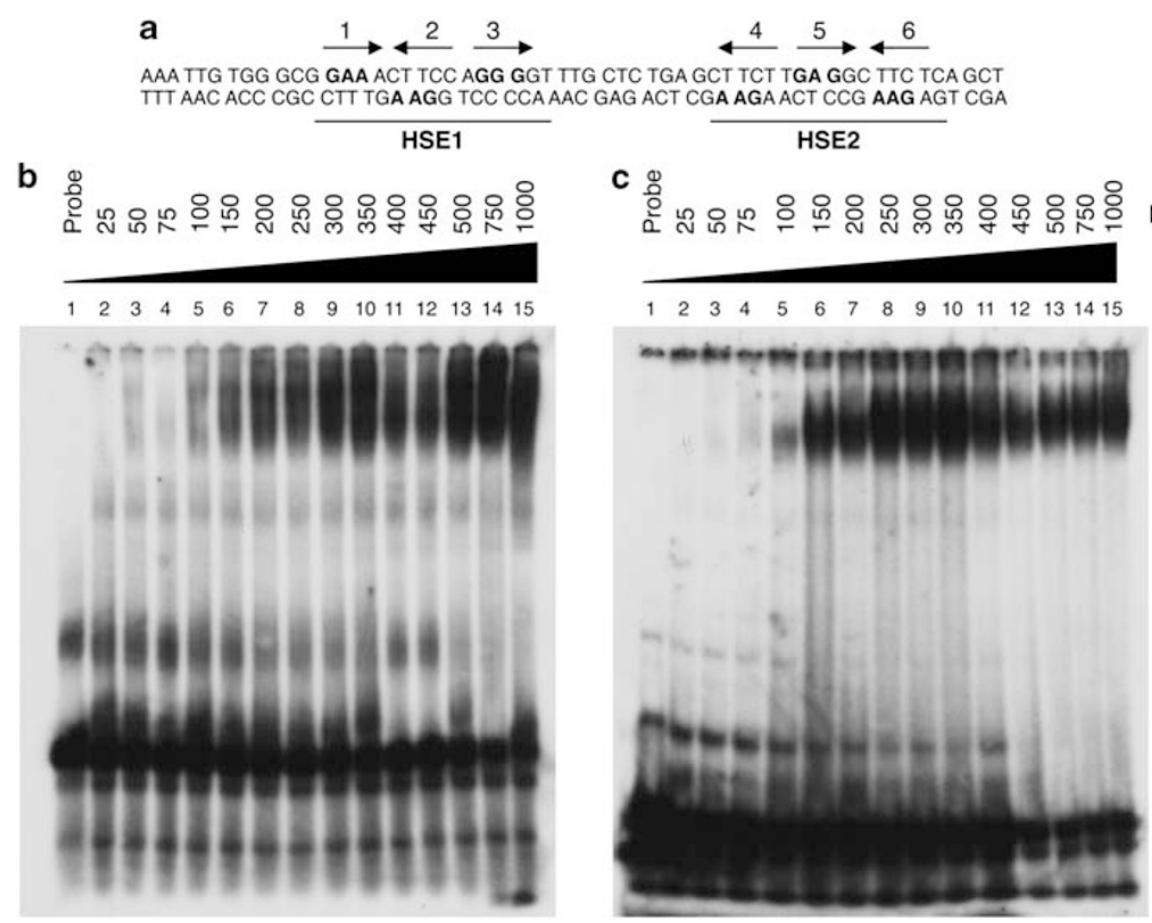

Figure 5 Putative heat shock elements (HSEs) within the FasL promoter. -295 to -225 region of the FasL promoter showing the putative HSEs (HSE1 (-276 to -262) and HSE2 (-250 to -236)). Numbers 1-6 indicate the nGAAn consensus repeats (a). Electromobility shift analysis (EMSA) of recombinant HSF-1 (0-1000 ng) binding to $\left[\alpha{ }^{32} \mathrm{P}\right]$ dATP-labeled oligonucleotides from the FasL promoter (b) or the proximal region from the human Hsp70 promoter (c). Data shown is representative of two experiments

a

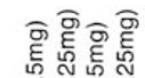

응ํㅇ $2 \times \mathrm{HSE} \quad 2 \times \mathrm{HSE}$

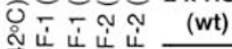

。

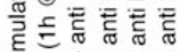

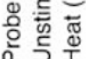

Heat $\left(1 \mathrm{~h} @ 42^{\circ} \mathrm{C}\right)$

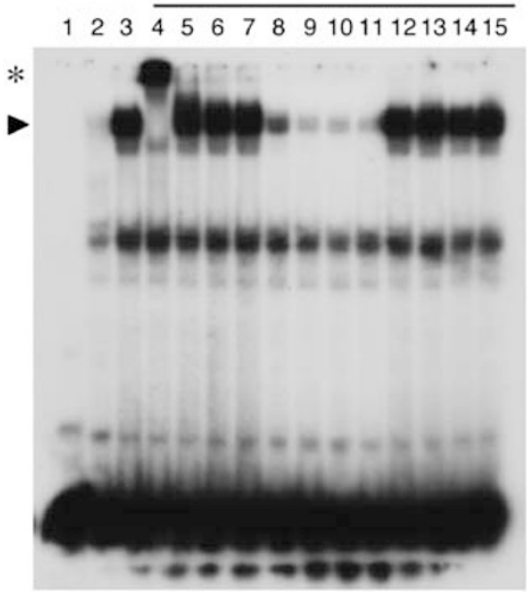

b

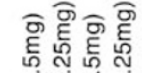

- 0 อ

তัญ

(wt) (mt)

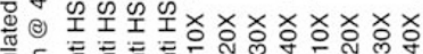

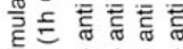

응

$++++$

Heat $\left(1 \mathrm{~h} @ 42^{\circ} \mathrm{C}\right)$

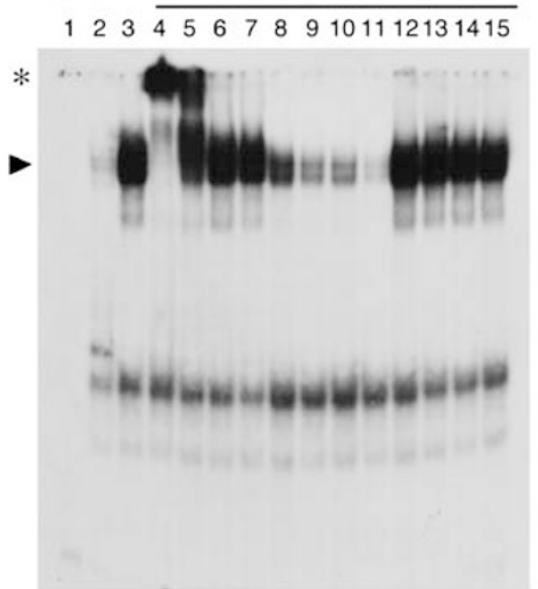

c

के छे के

응ํ HSE2 HSE2

ONT N (wt) (mt)

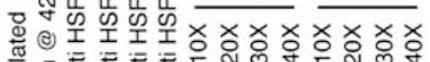

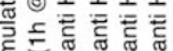

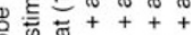

은

Heat $\left(1 \mathrm{~h} @ 42^{\circ} \mathrm{C}\right)$

$1 2 3 4 \longdiv { 5 6 7 8 9 1 0 1 1 1 2 1 3 1 4 1 5 }$

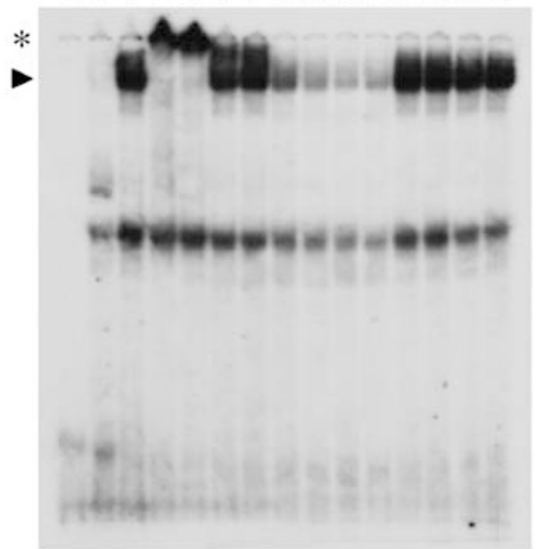

Figure 6 Oligonucleotides containing the putative HSEs from the FasL promoter compete for binding of HSF-1 to Hsp70 promoter. EMSA analysis using a $\left[\alpha-{ }^{32} \mathrm{P}\right] \mathrm{dATP}$ labeled oligonucleotide containing HSEs from the proximal region of the Hsp70 promoter incubated with nuclear extracts prepared from Jurkat T cells after heat shock (60 min at $42^{\circ} \mathrm{C}$ ). Extracts isolated from unstimulated cells served as a control. Heat shock-inducible activity is marked by an arrowhead and supershift analysis using anti-HSF-1 or HSF-2 antibodies show the specificity of binding (denoted by *). Cold competition was performed using unlabeled wild type (wt) or mutant (mt) oligonucleotides from the FasL promoter containing both HSEs: $2 \times$ HSE (wt) or $2 \times$ HSE (mt) (a); HSE1 (wt) or HSE1 (mt) (b) or HSE2 (wt) or HSE2 (mt) (c). Sequences of oligonucleotides used are included in Materials and Methods and data shown is representative of three repeat experiments 
a

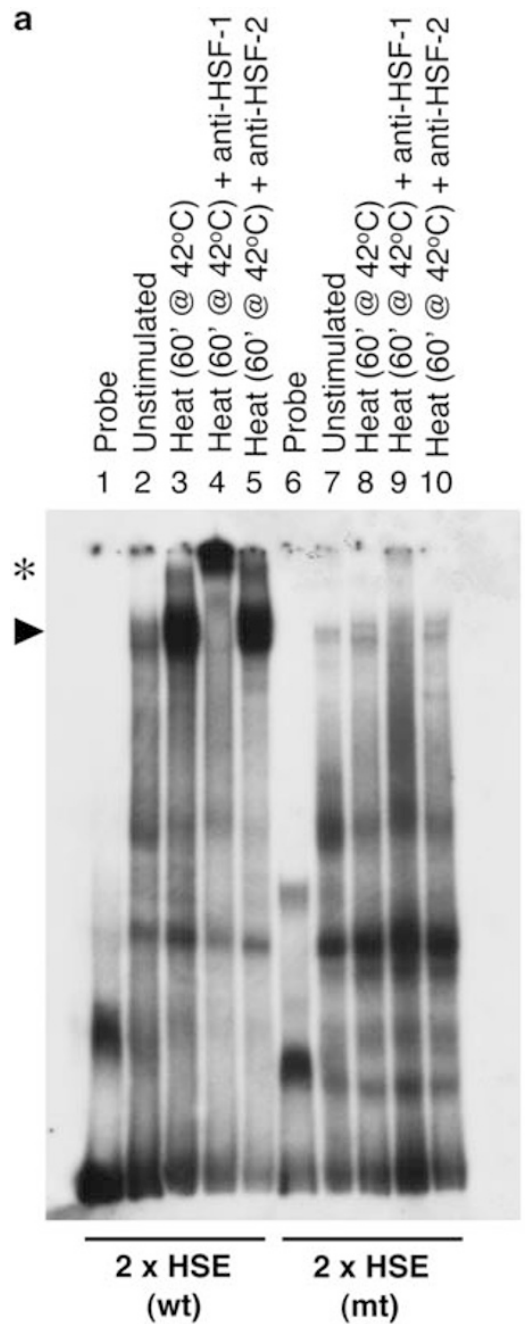

b
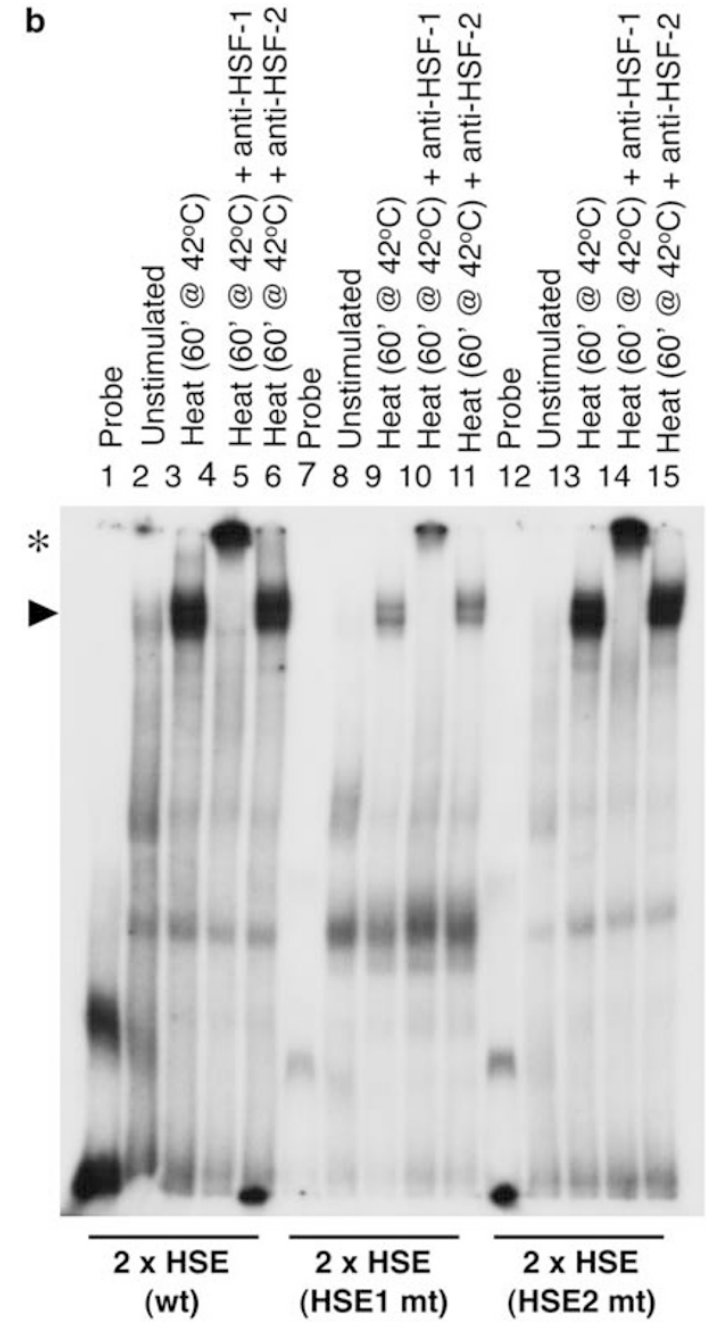

Figure 7 HSE1 and HSE2 cooperate for maximal HSF-1 binding. EMSA analysis using $\left[\alpha^{32} \mathrm{P}\right]$-dATP-labeled oligonucleotides containing both HSEs from the FasL promoter $(2 \times$ HSE $(w t))$ or mutations within both HSEs $((2 \times$ HSE $(\mathrm{mt}))(\mathbf{a})$, HSE1 $(2 \times$ HSE $($ HSE1 mt)) or HSE2 $(2 \times$ HSE $($ HSE2 $\mathrm{mt}))$ in the context of the $2 \times$ HSE oligonucleotide (b). Nuclear extracts were isolated from Jurkat T cells after heat shock ( $60 \mathrm{~min}$ at $42^{\circ} \mathrm{C}$ ) and analyzed for heat shock-inducible binding activity (marked by an arrowhead) and supershift using anti-HSF-1 or anti-HSF-2 antibodies is denoted by the asterisk (*). Extracts from unstimulated cells served as a control. Sequences of oligonucleotides used are included in Materials and Methods and data shown is representative of three repeat experiments

the ability of HSE2 to bind HSF-1. In contrast, mutation of key residues within HSE2 in the context of the full HSF-1-binding region did not reduce the ability of HSE1 to bind to HSF-1.

HSF-1 binds to HSE1 and HSE2 in a cooperative manner. We then tested the idea that cooperative interaction between the two elements generates the most stable binding, and accordingly, confers greater inducibility of gene expression. Using surface plasmon resonance (SPR), we were able to determine the binding constants of HSF-1 for the HSEs in the FasL promoter (Figure 9). We identified two components to the binding reaction between HSF-1 and the HSEs in both the Hsp70 and FasL promoters. The kinetic analysis and dissociation rate constants were determined according to a two state reaction (conformational change) model. The data obtained for each of the ligands (Hsp70, $2 \times$ HSE, HSE1 and HSE2) are shown in the sensorgrams in Figure 9a-d, respectively, and the calculated apparent affinity constant $K_{\mathrm{D}}(\mathrm{nM})$ values in Figure 9e. The $k_{\mathrm{a} 1}$ values for each of the ligands are almost identical, indicating that the initial binding reaction for HSF-1 is the same (Figure 9e). However, significant differences in the dissociation constant $\left(k_{\mathrm{d} 1}\right)$ for each of the oligonucleotides indicates a relatively unstable interaction between HSF-1 and HSE2 $\left(0.081 \mathrm{~s}^{-1}\right)$ as compared with that between HSF-1 and either HSE1 $\left(0.033 \mathrm{~s}^{-1}\right)$ or $2 \times \operatorname{HSE}\left(0.032 \mathrm{~s}^{-1}\right)$. Interaction between HSF-1 and the Hsp70 promoter displayed the greatest stability $\left(0.008 \mathrm{~s}^{-1}\right)$ (Figure 9e). The $k_{\mathrm{a} 2}$ and $k_{\mathrm{d} 2}$ values for both the Hsp70 promoter and the $2 \times$ HSE ligands indicate formation of a stable HSF-1/HSE complex with $K_{\mathrm{D}}$ values of 2.75 and $14 \mathrm{~nm}$, respectively. However, the interactions between HSF-1 and HSE1 or HSE2 show a reduced affinity and increased dissociation constants, suggesting that a reduced stabilization contributes to lower overall affinity $K_{\mathrm{D}}$ values of 29 and $112 \mathrm{nM}$, respectively. 
a
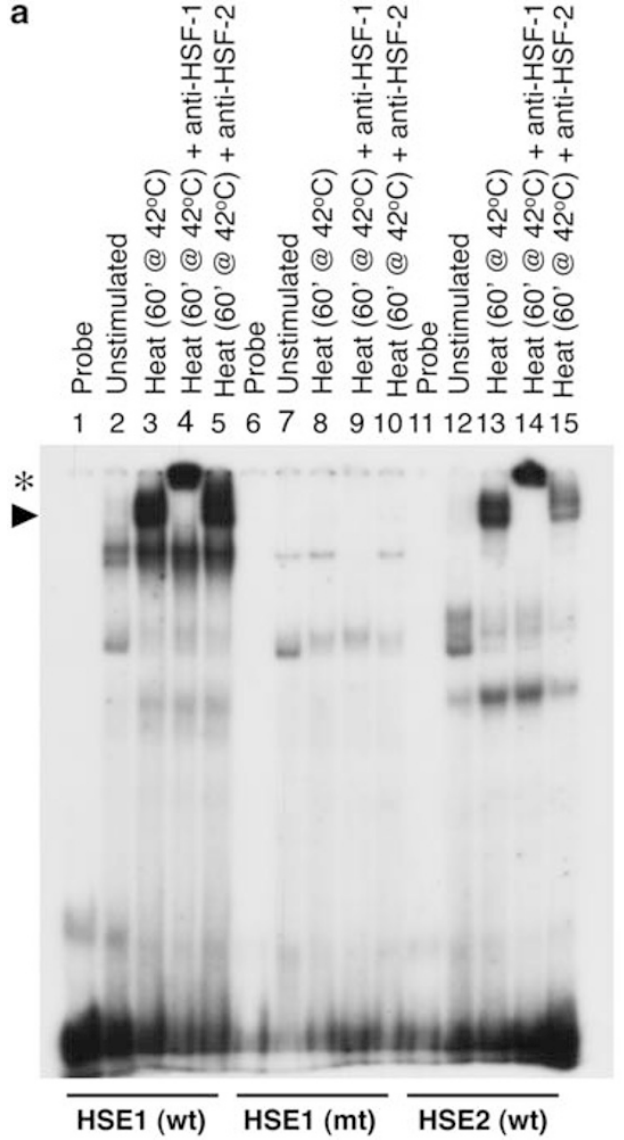

b
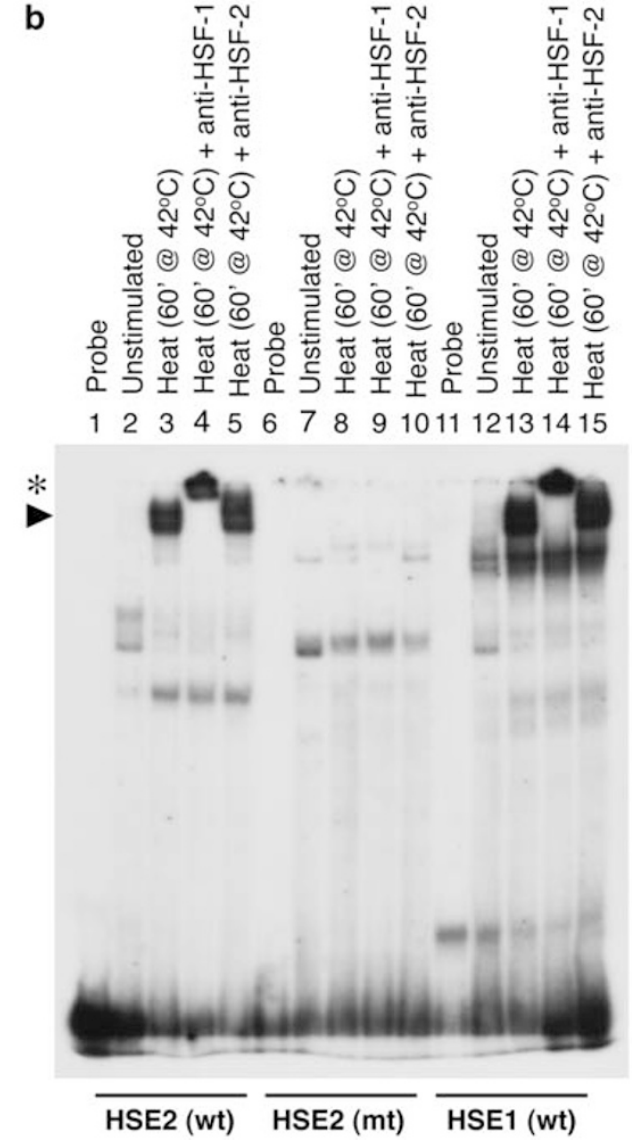

Figure 8 HSE1 and HSE2 from the FasL promoter can independently bind to HSF-1. EMSA analysis using $\left[\alpha^{-32} \mathrm{P}\right]-$ dATP-labeled oligonucleotides containing either (a) HSE1 or (b) HSE2 from the FasL promoter. Nuclear extracts were isolated from Jurkat T cells after heat shock $\left(60\right.$ min at $\left.42^{\circ} \mathrm{C}\right)$ and analyzed for heat shock-inducible binding activity (marked by an arrowhead) and supershift using anti-HSF-1 or HSF-2 antibodies (denoted by *). Specificity of binding was confirmed using oligonucleotides containing mutations of each of the key residues within the individual pentameric repeats (HSE1 (mt) or HSE2 (mt). Extracts isolated from unstimulated cells served as a control. Sequences of oligonucleotides used are included in Materials and Methods and data shown is representative of three repeat experiments

HSF-1 induces the expression of the FasL promoter through distinct regions. To directly test whether the HSEs in the FasL promoter were relevant for driving gene expression, we cloned oligonucleotides containing three repeats of the region we suspected to harbor (i) both putative HSEs or (ii) each of HSE1 or HSE2 into constructs containing the minimal IL-2 promoter and a luciferase reporter. ${ }^{26}$ The promoter construct containing both HSE1 and HSE2 was most sensitive to the over-expression of HSF-1 and showed the greatest fold induction (Figure 10a) (approximately 250-fold compared with HSE1 alone (five-fold) and the FasL promoter (12-fold)) (Figure 10d). HSE2 failed to drive promoter activity (Figure 10c). Comparable results were observed using Jurkat cells (data not shown). We conclude that the FasL promoter contains consensus-binding elements for HSF-1 that are competent to drive FasL promoter expression, but that both HSE1 and HSE2 must be present to induce optimal activity. This is likely because of a functional co-operation between these two elements that is reflected in the differential-binding affinity of HSF-1 for the individual elements.

\section{Discussion}

The aberrant expression of FasL is implicated in autoimmune disease and the failure to induce the peripheral deletion of activated $T$ cells to restore immune homeostasis after antigenic challenge. ${ }^{28,29}$ The physiological significance of the HSF-1-mediated regulation of FasL in the context of immune function is unclear and although HSF-1 null mice display several defects in immune regulation, ${ }^{16,30}$ no studies have addressed the potential function of HSF-1 under conditions in which FasL is required for immune function.

During the fever phase of infection, body temperature is raised as a consequence of increased levels of circulating pyrogenic cytokines and functions to help minimize the duration of infection and facilitate pathogen clearance. ${ }^{11}$ Elevated temperature can also regulate the secretion of several of the cytokines essential for survival from acute infection. ${ }^{13}$ Interestingly, the transcriptional activity of HSF-1 has been linked to the regulation of TNF $\alpha,{ }^{14} \mathrm{IL}-1 \beta^{15,31}$ and IL$6^{16}$ expression, all of which are essential components of immune defense. Furthermore, Fas activation can inhibit heat-induced activation of HSF-1, ${ }^{32}$ suggesting a feedback 

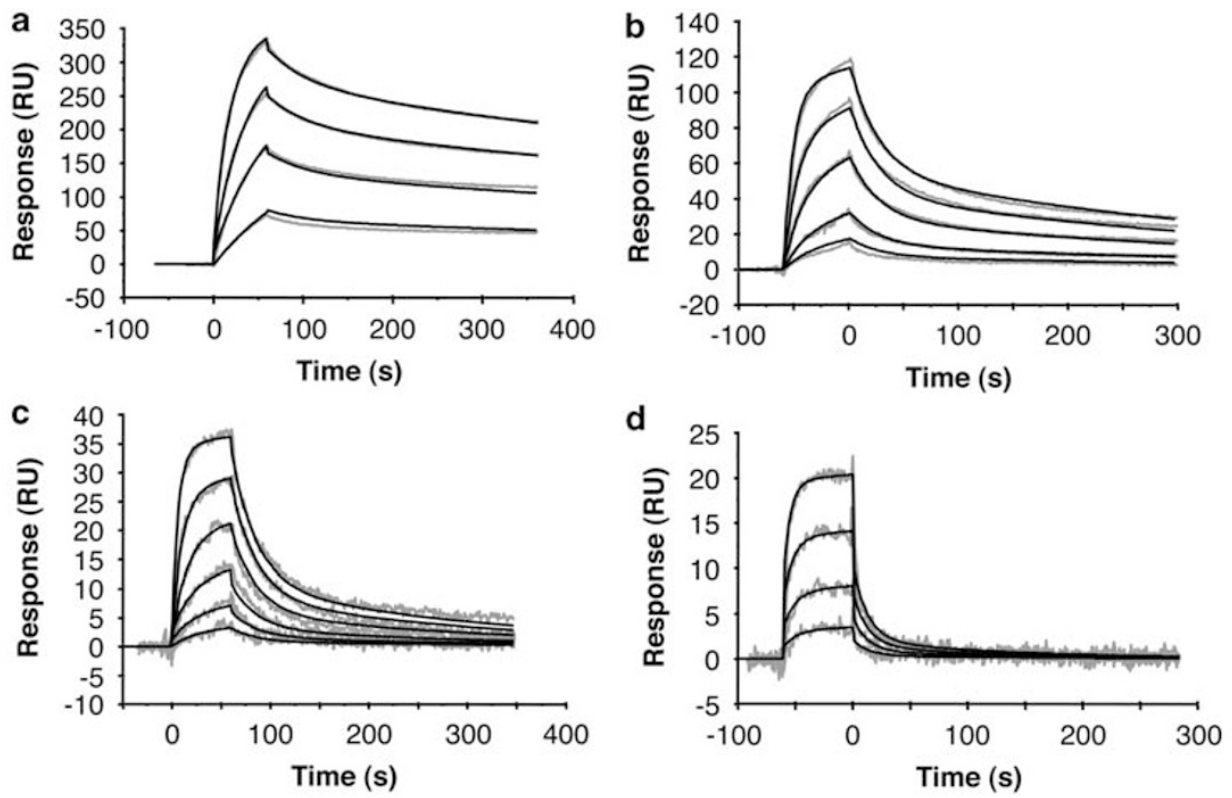

\begin{tabular}{|c|c|c|c|c|c|}
\hline LIGAND & $\mathbf{K}_{\mathrm{D}}(\mathbf{n M})$ & $\mathbf{k}_{\mathrm{a} 1}\left(\mathbf{\times} 10^{6} \mathbf{M}^{-1} \mathbf{s}^{-1}\right)$ & $\mathbf{k}_{\mathrm{d} 1}\left(\mathbf{s}^{-1}\right)$ & $\mathbf{k}_{\mathrm{a} 2}\left(\mathbf{s}^{-1}\right)$ & $\mathbf{k}_{\mathrm{d} 2}\left(\mathbf{s}^{-1}\right)$ \\
\hline Hsp70pr & $2.75+/-2.60$ & $0.52+/-0.394$ & $0.008+/-0.000$ & $0.013+/-0.001$ & $0.002+/-0.001$ \\
\hline $2 \times$ HSE & $14.44+/-6.22$ & $0.59+/-0.240$ & $0.032+/-0.003$ & $0.011+/-0.004$ & $0.003+/-0.000$ \\
\hline HSE1 & $29.30+/-0.91$ & $0.53+/-0.093$ & $0.033+/-0.002$ & $0.006+/-0.001$ & $0.005+/-0.000$ \\
\hline HSE2 & $112+/-1.79$ & $0.51+/-0.088$ & $0.081+/-0.009$ & $0.005+/-0.001$ & $0.011+/-0.005$ \\
\hline
\end{tabular}

Figure 9 Binding studies of HSF-1 to HSEs in the FasL promoter using BIAcore. Biotinylated oligonucleotides (Hsp70pr, $2 \times$ HSE, HSE1 and HSE2) were immobilized on a streptavidin coated sensor chip and samples of serially diluted HSF-1 (5-200 nM) analyzed on one of Hsp70 (a), $2 \times$ HSE (b), HSE1 (c) or HSE2 (d) sensor surface. The experimental data (gray lines) and the suggested fit to a two state reaction model (black lines) are shown. Sequence details and the binding constants for each ligand (Hsp70, $2 \times$ HSE, HSE1 and HSE2) were determined according to the two state reaction (conformational change) model as detailed in Materials and Methods (e)

loop between Fas/FasL signaling events and regulation of events associated with elevation of body temperature during fever. TNF- $\alpha$, the transcription of which is suppressed by HSF $-1,{ }^{14}$ is also able to inhibit heat-induced activation of HSF-1 through induction of phosphatases that presumably target HSF-1 to attenuate its activity. ${ }^{33}$ Although we do not understand the significance of HSF-1-mediated regulation of FasL expression, several scenarios emerge in which this regulatory loop could impact immune function.

We showed that hyperthermia induced FasL expression that was more pronounced in both Jurkat $T$ cells and primary human PBLs activated by PMA/ion or anti-CD3. This effect was restricted to FasL and was not observed with other members of the TNF superfamily, TRAIL and TNF. The enhanced expression of FasL gene expression in activated Jurkat $T$ cells exposed to elevated temperature correlated with increased FasL protein expression that induced enhanced killing in $\mathrm{Fas}^{+}$target cells.

Similar observations by Cippitelli et al. ${ }^{22}$ describe a hyperthermia response element in the FasL promoter extending from -195 immediately $5^{\prime}$ of the translational start site. We defined an HSF-1-binding region in the FasL promoter extending from -276 to -236 upstream of the translational start site that confers heat-inducible gene expression. Although Cippitelli et al. ${ }^{22}$ observed that heat stress cooperated with $\mathrm{AP}-1$ and $\mathrm{NF}-\kappa \mathrm{B}$ to increase FasL reporter activity, we showed that HSF-1 drives the FasL promoter through a region devoid of either $\mathrm{AP}-1$ or $\mathrm{NF}-\kappa \mathrm{B}$ binding sites. Cippittelli et al. ${ }^{22}$ noted the necessity for the distal NFAT site ${ }^{26}$ in mediating the activity of HSF-1 on the FasL promoter (notably, however, this site lies outside of their proposed region of hyperthermia sensitivity). Significantly, inactivation of this NFAT site would simultaneously mutate one of the HSF-1-binding sites within the HSE1 that we describe here.

The region encompassing HSE1 was earlier identified as important for FasL expression in response to TCR signals and IL-2 stimulation. ${ }^{26}$ Therefore, it is a likely component of a complex regulatory region containing overlapping-binding sites for several transcription factors. We have not sought to determine how HSF-1 influences the avidity or affinity of additional transcription factor-binding sites, but it is interesting to speculate that the response of the FasL promoter to different signals may engage different combinations of transcription factors to generate stress-specific gene expression. We have revealed a functional cooperation between HSF-1 induced through hyperthermia and TCR signals whether this represents another transcription factor that is activated directly in response to TCR signals that functions in cooperation with HSF-1 or alternatively, whether signals that 
a

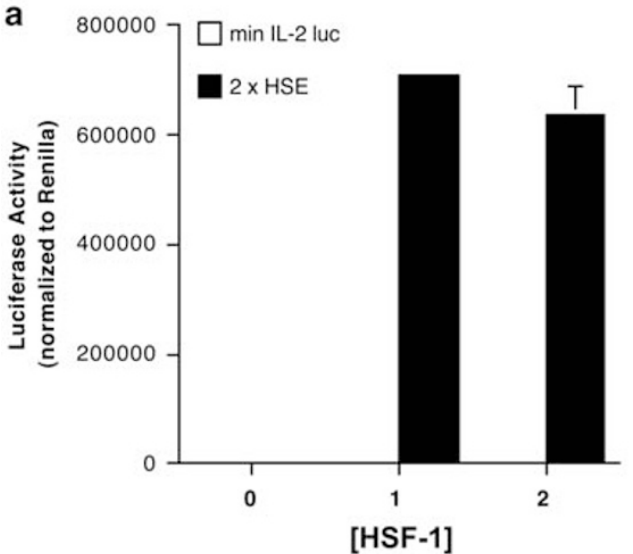

c

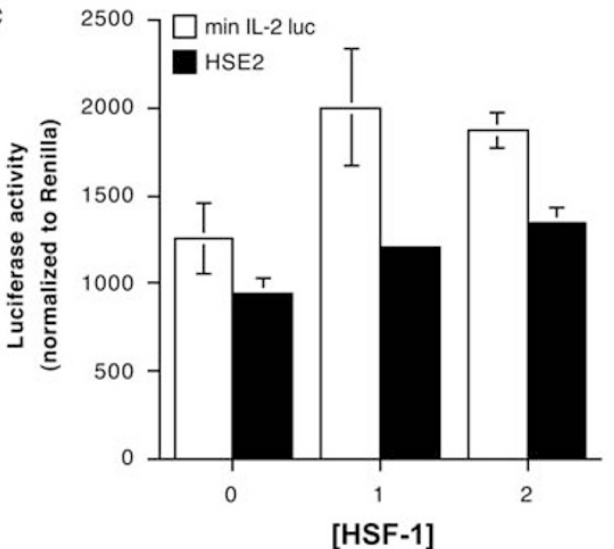

b

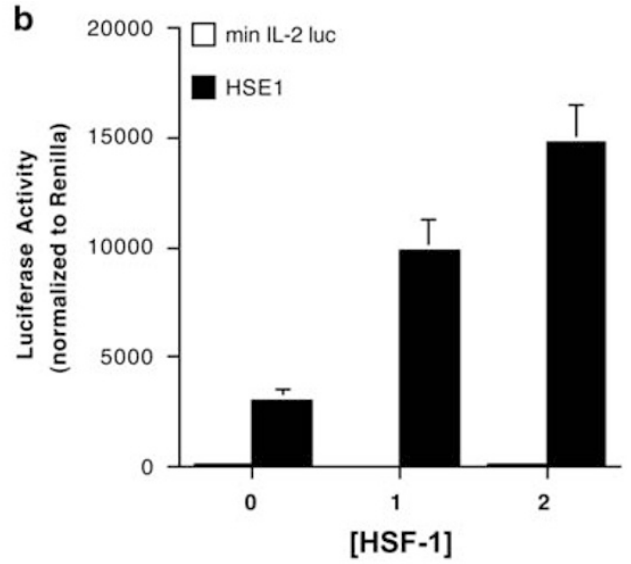

d

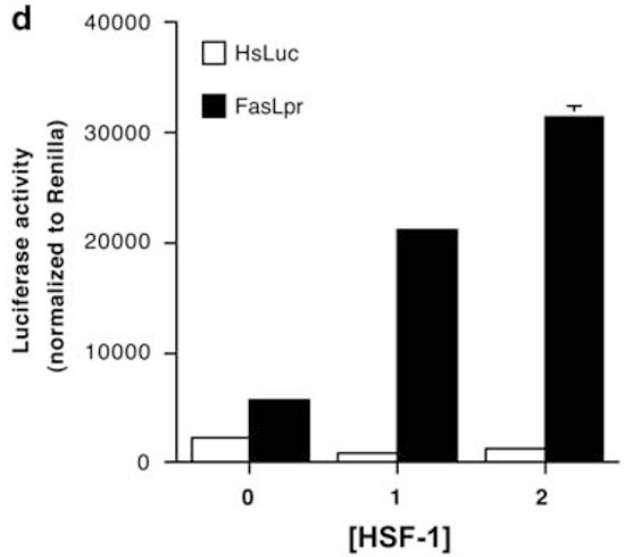

Figure 10 Putative HSEs from the FasL promoter are induced by HSF-1 to drive the expression of a luciferase reporter. MCF-7 cells were transfected with one of the luciferase reporter constructs containing three repeats of both putative HSEs $(2 \times \mathrm{HSE})(\mathbf{a})$, HSE1 (b) or HSE2 (c) from the FasL promoter together with an expression construct for HSF-1. For comparison, transfection of cells with the $1.2 \mathrm{~kb}$ FasL promoter plus HSF-1 is shown (d). After $24 \mathrm{~h}$, cells were harvested and Firefly luciferase activities measured and normalized to an internal Renilla luciferase standard. Data shows the average of triplicates from one representative experiment performed at least three times

arise from TCR activation impact on HSF-1 function is currently unclear.

We show that HSF-1 can bind in a cooperative manner to a defined region within the FasL promoter that correlates with upregulation of endogenous FasL gene expression. The cooperation between HSE1 and HSE2 could reflect a direct protein-protein interaction, whereby HSF bound to one of the elements facilitates the binding of additional HSF trimers. Alternatively, binding of HSF to its low affinity site may depend on altered DNA topology generated by occupation of the other site. Cooperation between two adjacent HSF-1-binding sites is optimal when separated by $10.5 \mathrm{bp}$, which corresponds to one turn of the DNA helix. ${ }^{34}$ The two HSEs in the FasL promoter are separated by $11 \mathrm{bp}$, which represents ideal spacing for optimal functional interaction based on a number of earlier studies examining the optimal periodicity for HSEs to sustain maximal transcription. ${ }^{5,6}$ FasL promoter constructs that contain either HSE1 or HSE2 show only a marginal inducibility in response to heat or to HSF-1 over-expression, whereas those containing both HSE1 and HSE2 show a much-enhanced response, indicative of cooperative binding and activation by HSF-1. This pattern is consistent with the transcriptional regulation of heat shock genes. ${ }^{34}$
Our findings clearly show, for the first time, a direct association of HSF-1 with the FasL promoter and define two novel HSEs that function in a cooperative manner to optimally induce FasL promoter activity. This characterization is placed into a functional context by showing that hyperthermia elevates endogenous FasL expression in an HSF-1-dependent manner. These findings extend the function for the stress response beyond the regulation of Hsp gene expression to encompass the potential for HSF-1 as a regulator of immune function. Furthermore, the novelty of defining a hyperthermic response of the FasL promoter through a pathway involving HSF-1 bears particular significance in the context of the fever response. Elevated body temperature has been long recognized as an effector of optimal immune function, although the underlying mechanisms for this effect of hyperthermia remain somewhat elusive. The activation of HSF-1 at fever-like temperatures and its regulation of temperature-sensitive gene expression implicates HSF-1 as an important regulator of immune regulation and refines our understanding of how hyperthermia may modify immune function. The inclusion of FasL as an HSF-1 target extends the significance of HSF-1 in immune function and points to a potential function for the stress response in $\mathrm{T}$ cell function. FasL expression is a critical 
regulator of $\mathrm{T}$ cell survival in the context of peripheral deletion and is essential for the restoration and maintenance of immune homeostasis. Placement of HSF-1 in this pathway raises the notion that HSF-1 could have an essential function in the regulation of adaptive immunity. In addition, one of the HSF-1-binding elements we describe overlaps with an NF-AT site described earlier as crucial in the regulation of FasL after TCR activation. This raises the possibility that HSF-1 might modify NF-AT binding either positively in a manner analogous to the synergy observed with NF-AT and AP1 or negatively by direct competition to regulate FasL expression in response to TCR activation. In fact, signals emanating from TCR activation including ROS can activate both FasL expression and HSF-1 - this potentially extends the function of HSF-1 in hyperthermia-induced FasL expression to encompass involvement in TCR signaling events to impact FasL expression and $T$ cell function.

\section{Materials and Methods \\ Cytotoxicity assay. Jurkat $T$ cells were activated by overnight incubation with plate bound anti-CD3 (clone OKT3) $(1 \mu \mathrm{g} / \mathrm{ml})$ (eBioscience, San Diego, CA, USA) plus soluble anti-CD28 (clone CD28.2) $(2 \mu \mathrm{g} / \mathrm{ml})$ (eBioscience) before heat shock and overnight recovery at $37^{\circ} \mathrm{C}$. Cells were then mixed with L1210 or L1210-Fas target cells at a 10:1 effector to target ratio. Target cells were distinguished by staining with PH67GL (Sigma-Aldrich, St Louis, MO, USA) according to manufacturer's instructions. After $24 \mathrm{~h}$, cells were resuspended in PBS, propidium iodide (PI) $(1 \mu \mathrm{g} / \mathrm{ml})$ added and immediately assessed through flow cytometry.}

FasL staining. Jurkat T cells $\left(1.5 \times 10^{6}\right)$ were plated in triplicate into 48 -well plates and stimulated overnight with media alone or plate bound anti-CD3 $(1 \mu \mathrm{g} / \mathrm{ml})$ and soluble anti-CD28 $(2 \mu \mathrm{g} / \mathrm{ml})$. The following day, cells were incubated at 37,42 or $44^{\circ} \mathrm{C}$ for $1 \mathrm{~h}$. Immediately after heat-shock, fresh media containing $1.5 \mu \mathrm{M} \mathrm{1,10}$ phenanthroline was added. After $16 \mathrm{~h}$ cells were washed and resuspended in $150 \mu \mathrm{l}$ FACS buffer containing $1.5 \mu \mathrm{g}$ of anti-FasL-biotin (clone NOK-1) for $35 \mathrm{~min}$ at room temperature. Cells were then washed and resuspended in $150 \mu \mathrm{l}$ FACS buffer containing a 1:1000 dilution of streptavidin-Alexa 488 for $15 \mathrm{~min}$ at room temperature. Cells were washed twice and analyzed on a FACS Calibur flow cytometer (Becton Dickinson Biosciences, San Jose, CA, USA).

Preparation of nuclear extracts. Nuclear extracts were prepared from Jurkat T cells routinely cultured in RPMI medium supplemented with $10 \%$ fetal calf serum and $5 \mathrm{mM}$ glutamine. Cells were exposed to heat shock $\left(42{ }^{\circ} \mathrm{C}\right.$ for $\left.60 \mathrm{~min}\right)$ before preparation of extracts from $1 \times 10^{8}$ cells per sample. After washing with cold PBS, cells were resuspended in cell lysis buffer (Buffer A: $10 \mathrm{mM}$ HEPES plus $10 \mathrm{mM} \mathrm{NaOH}$ (pH 7.9), $20 \mathrm{mM} \mathrm{NaF}, 1 \mathrm{mM} \mathrm{Na}_{3} \mathrm{VO}_{4}, 1 \mathrm{mM}$ EDTA and $0.1 \mathrm{mM} \mathrm{EGTA}$ supplemented with $1 \mathrm{mM}$ DTT, $1 \mu \mathrm{g} / \mathrm{ml}$ Aprotinin, $1 \mu \mathrm{g} / \mathrm{ml}$ Leupeptin and $5 \%$ NP40). Nuclei were pelleted with a 2-min spin at 2200 r.p.m. and then resuspended in a pellet size volume of nuclear extract buffer (Buffer B: Buffer A minus NP-40 plus $0.42 \mathrm{M} \mathrm{NaCl}$ and $20 \%$ glycerol). Nuclei were vortexed for several 5 -s bursts and the extracts then centrifuged at 14000 r.p.m. for $15 \mathrm{~min}$ at $4^{\circ} \mathrm{C}$. Aliquots were stored at $-80^{\circ} \mathrm{C}$ until ready for use.

Probe labeling. Oligonucleotides were annealed using $5 \mu \mathrm{g}$ each of the sense and antisense oligonucleotides ( $100 \mathrm{ng} / \mu$ l stock solution), $5 \times$ annealing buffer (200 mM Tris- $\mathrm{HCl} \mathrm{pH7.5,} 100 \mathrm{mM} \mathrm{MgCl}_{2}, 250 \mathrm{mM} \mathrm{NaCl}$ ) and water in a total volume of $100 \mu \mathrm{l}$. After heating to $65^{\circ} \mathrm{C}$ for $10 \mathrm{~min}$, the reactions were allowed to cool to room temperature. Annealed oligonucleotides were then stored at $-20^{\circ} \mathrm{C}$ until ready for use. The labeling reaction was performed using $400 \mathrm{ng}$ of annealed oligonucleotide, $1 \mu \mathrm{l} \mathrm{T4}$ polynucleotide kinase (PK) (New England BioLabs, Ipswich, MA, USA), $10 \times$ T4 PK buffer, $4 \mu$ l of $\left[\gamma^{32} \mathrm{P}\right]$-adenosine $5^{\prime}$-triphosphate $(6000 \mathrm{Ci} /$ $\mathrm{mM}$ ) (Perkin Elmer, Boston, MA, USA) and water to a total volume of $40 \mu \mathrm{l}$. After incubation at $37^{\circ} \mathrm{C}$ for $30 \mathrm{~min}$, an additional $1 \mu \mathrm{l}$ of T4 PK was added and incubation continued for a further $30 \mathrm{~min}$. Unincorporated $\left[\gamma^{32} \mathrm{P}\right]-\mathrm{ATP}$ was removed using a Bio-Rad Micro Bio-Spin 30 chromatography column (Hercules, CA, USA) according to the manufacturer's instructions. A total of $1 \mu \mathrm{l}$ of probe was removed to assess labeling efficiency using a Beckman LS6500 scintillation counter (Beckman Coulter, Brea, CA, USA) and the remaining labeled oligonucleotide diluted to $20000 \mathrm{cpm} / \mu$.

Electrophoretic mobility shift assays. Nuclear extracts or recombinant HSF-1 protein (StressGen Bioreagents, Ann Arbor, MI, USA) were tested for DNA-binding ability using wt or mt (mutations are indicated by bold text) blunt ended synthetic oligonucleotides from the relevant regions of the $\mathrm{Hsp} 70$ and FasL promoters. The sequences used were as follows: hHsp70 (proximal) $5^{\prime}$ GGAGGCGAAACCCCTGGAATATTCCCGACCTGGCA-3'; $2 \times$ HSE (wt) $5^{\prime}$-TGG GCGGAAACTTCCAGGGGTTGCTCTGAGCTTCTTGAGGCTTCTCAGCT-3'; $2 \times$ HSE (mt) 5'-TGGACGAAAATTTTTAAAGGTTTGTTCTGAGCTTTTTAAAGCTTTTTA GCT-3'; $2 \times$ HSE (HSE1 mt) 5'-TGGACGAAAATTTTTAAAGGTTTGTTCTGAG CTTCTTGAGGCTTCTCAGCT-3'; $2 \times$ HSE (HSE2 mt) $5^{\prime}$-TGGGCGGAAACTTCC AGGGGTTTGCTCTGAGCTTTTTAAAGCTTTTTAGCT-3'; HSE1 (wt) 5'-TGGGC GGAAACTTCCAGGGGTTTGC-3'; HSE1 (mt) 5'-TGGACGAAAATTTTTAAAGG

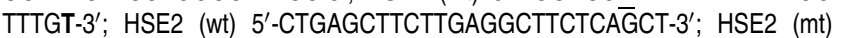
$5^{\prime}$ CTGAGCTTTTTAAAGCTTTTTAGCT-3'. Oligonucleotides labeled with $\left[\gamma^{32} \mathrm{P}\right]-$ ATP were used at $20000 \mathrm{cpm}$ per sample for the supershift gels and at $25 \mathrm{ng}$ DNA for the binding affinity studies. Samples were prepared in $20 \mu \mathrm{l}$ with $5 \mu \mathrm{g}$ of nuclear extracts or relevant HSF-1 protein concentration, $0.02 \mathrm{M} \mathrm{DTT}, 0.50 \mu \mathrm{g}$ of poly(dl-dC) (Amersham Biosciences, Piscataway, NJ, USA) and $0.5 \times$ binding buffer $(1 \times$ : $20 \mathrm{mM}$ Tris (pH 7.9), $1 \mathrm{mM}$ EDTA, $50 \mathrm{mM} \mathrm{KCl}, 10 \%$ glycerol, $0.05 \%$ nonidet $\mathrm{P}-40$ ). For supershift and competition studies, samples were incubated at room temperature in a waterbath for $15 \mathrm{~min}$, probe was then added followed by cold (unlabeled) oligonucleotide where required. Samples were then incubated for an additional $12 \mathrm{~min}$ at room temperature before addition of the relevant antibody for the detection of complex formation through supershift (anti-HSF-1 (PA3-107) (Affinity Bioreagents, Golden, CO, USA) or anti-HSF-2 (SPA-960) (StressGen Bioreagents)) and continued incubation for an additional $12 \mathrm{~min}$. For the binding affinity studies using recombinant HSF-1 protein, samples were incubated at room temperature for $15 \mathrm{~min}$ before addition of the probe and an additional $15 \mathrm{~min}$ incubation. Samples were resolved on $4 \%$ acrylamide gels at $250 \mathrm{~V}$ for $2.5 \mathrm{~h}$, at $4{ }^{\circ} \mathrm{C}$ in $0.5 \times$ Tris-Borate-EDTA. Gels were pre-run for $30 \mathrm{~min}$ before loading. Gels were then dried and subjected to autoradiography.

Transient transfection and luciferase measurement. A total of $2 \times 10^{7}$ Jurkat T cells were washed twice with and resuspended in serum-free medium $(500 \mu \mathrm{ll})$ before transfer to a 4-mm gap electroporation cuvette (InVitrogen, Carlsbad, CA, USA). The appropriate amounts of each luciferase reporter $(20 \mu \mathrm{g})$ plus an HSF-1 expression construct $(0-20 \mu \mathrm{g})$ were added to the cells and mixed well. All samples were normalized to contain the same amount of DNA using empty vector (HsLuc, min-IL-2 or pcDNA3) and also included Renilla luciferase $(1 \mu \mathrm{g})$ as an internal control. Cells were then electroporated at $250 \mathrm{~V}$ and $960 \mu \mathrm{F}$ in a Bio-Rad Gene Pulse II. MCF-7 cells were plated at $2 \times 10^{5}$ cells/well in DMEM medium supplemented with $10 \%$ fetal calf serum and $5 \mathrm{mM}$ glutamine and transfected with the appropriate luciferase reporter ( $0.5 \mu \mathrm{g} /$ well) plus an HSF-1 expression construct $(0-2 \mu \mathrm{g})$ using FuGENE 6 transfection reagent (Roche Diagnostics, Indianapolis, IN, USA) according to the manufacturer's instructions. All wells were normalized to contain the same amount of DNA using empty vector (HsLuc, min-IL-2 or pcDNA3) and also included Renilla luciferase $(0.1 \mu \mathrm{g})$ as an internal control. The luciferase reporter constructs examined contained $1.2,{ }^{21} 0.9^{21}$ or $0.486 \mathrm{~kb}^{26}$ regions of the $\mathrm{hFasL}$ promoter. The Hsp70 promoter construct was kindly provided by Dr. Richard Morimoto (Northwestern University, IL, USA) ${ }^{3}$ and the pCDNA3-hHSF-1 expression construct was obtained from Dr. Richard Voellmy (University of Miami School of Medicine, Miami, FL, USA). ${ }^{1,24}$ Reporter constructs containing three repeats of either HSE1 (TGGGCGGAAACTTCCAGGGGTTTGC), HSE2 (CTGAGCTTCT TGAGGCTTCTCAGCT) or both $(2 \times$ HSE) (TGGGCGGAAACTTCCAGGGGTTTG CTCTGAGCTTCTTGAGGCTTCTCAGCT) were cloned into the min-IL-2 reporter vector. ${ }^{26}$

After transfection for 18-24h, some experiments included an additional overnight incubation with PMA $(50 \mathrm{nM})$ and ionomycin $(1 \mu \mathrm{g} / \mathrm{ml})$ or exposure to heat shock followed by recovery at $37^{\circ} \mathrm{C}$. Cells were then harvested, washed three times with PBS and resuspended in $100 \mu \mathrm{l}$ of passive lysis buffer (Promega, San Luis Obispo, CA, USA). Cell debris was removed by centrifugation and Firefly and Renilla luminescence assessed according to the manufacturer's instructions (Promega) using a Monolight 2010 luminometer (Analytical Luminescence Laboratory, San Diego, CA, USA). 
Real-time reverse transcription-PCR. Jurkat T cells were activated by overnight incubation with PMA $(50 \mathrm{nM})$ plus ionomycin $(1 \mu \mathrm{g} / \mathrm{ml})$ or plate bound antiCD3 (clone OKT3) $(1 \mu \mathrm{g} / \mathrm{ml})$ plus or minus anti-CD28 (clone CD28.2) $(2 \mu \mathrm{g} / \mathrm{ml})$. Total RNA was then isolated from $1-5 \times 10^{6}$ Jurkat cells at various time points using Trizol $^{-}$(InVitrogen) according to the manufacturer's instructions. A total of $0.5 \mu \mathrm{g}$ RNA was reverse transcribed using Moloney murine leukemia virus reverse transcriptase (InVitrogen) in a total volume of $40 \mu$ that included random hexamers $(2.5 \mu \mathrm{M})$ (InVitrogen), dNTPs $(100 \mu \mathrm{M})$ (InVitrogen), DTT $(10 \mu \mathrm{M})$ and RNAseOut (InVitrogen). Real-time PCR was performed using a 7900HT Fast Real-time PCR system (Applied Biosystems, Foster City, CA, USA) and the SyBr Green detection protocol as outlined by the manufacturer (Applied Biosystems). Briefly, $12 \mathrm{ng}$ of total CDNA, $100 \mathrm{nM}$ (each) primer and $12.5 \mu \mathrm{l}$ SYBR master mix ( $2 \mathrm{x}$ ) were used in a total volume of $25 \mu$ l.

Primary PBLs were isolated from venous blood drawn from healthy volunteers, purified by FICOLL gradient and cultured in RPMI supplemented with 10\% FCS, $2 \mathrm{mM}$ Glutamax (InVitrogen), penicillin and streptomycin in plates coated with anti$\mathrm{CD} 3$ or anti-CD3 and anti-CD28 overnight at $37^{\circ} \mathrm{C}$ at $5 \% \mathrm{CO}_{2}$. Cells were heat shocked at $44^{\circ} \mathrm{C}$ for $60 \mathrm{~min}$ and allowed to recover at $37^{\circ} \mathrm{C}$ for $8 \mathrm{~h}$. Control cells were maintained at $37^{\circ} \mathrm{C}$ before the 8-h recovery period. RNA was purified using RNeasy column (QIAGEN, Valencia, CA, USA), reverse transcribed with Superscript III reverse transcriptase (InVitrogen) and analyzed by real-time PCR (ABI Prism 7000, Applied Biosystems).

The forward $(F)$ and reverse $(R)$ primers for human FasL, TRAIL, TNF, Hsp70 and 18S were as follows: $5^{\prime}$-GATCTACTGGGTGGACAGCAGTG-3' (F) and $5^{\prime}$-TT GGACAGGGAAGAACTGTGC-3' (R) (Jurkat) or 5'-CAGTCCACCCCCTGAAAAAA AA-3' (F) and $5^{\prime}$-CCAGAGGCATGGACCTTGAG-3' (R) (human PBL) (FasL); $5^{\prime}$-GCTCTGGGCCGCAAAAT-3' (F) and $5^{\prime}$-TGCAAGTTGCTCAGGAATGAA-3' $(\mathrm{R})$ (TRAIL); 5'-GGAGAAGGGTGACCGACTCA-3' (F) and 5- TGCCCAGACTCGGCA AAG-3' (R) (TNF); $5^{\prime}$-GAGAAGGACGAGTTTGAGCACAA-3' (F) and $5^{\prime}$ TGGTACA GTCCGCTGATGATG-3' (R) (Hsp70) and 5'-ACATCCAAGGAAGGCAGCAG-3' (F) and $5^{\prime}$-TCGTCACTACCTCCCCGG-3' (R) (Jurkat) or $5^{\prime}$-ATGGCCGTTCTTAGTT GGTG-3' (F) and 5'-ATGCCAGAGTCTCGTTCGTT-3' (R) (human PBL) (18S).

SPR: BIAcore. Binding between HSF-1 (StressGen Bioreagents) and double stranded pre-annealed biotinylated oligonucleotides from the Hsp70 or FasL promoters was detected by SPR using a BIAcore X biosensor (BIAcore, Piscataway, NJ, USA). Neutravidin (Pierce, Rockford, IL, USA) was dissolved in $10 \mathrm{mM} \mathrm{Na}$-acetate $(\mathrm{pH} 5)$ and $3000 \mathrm{RU}$ was immobilized on the surface of $\mathrm{CM} 4$ sensorchips (BIAcore), earlier activated by $N$-hydroxysuccinimide $(0.05 \mu \mathrm{M})$ and $N$ hydroxysuccinimide- $N$-ethyl- $N$ '-(diethylaminopropyl)carbodiimide $(0.2 \mu \mathrm{M})$. Free neutravidin was removed with three successive injections of $10 \mathrm{mM} \mathrm{HCl}(1 \mathrm{~min}$ at $100 \mu / / \mathrm{min}$ ) followed by blocking with $1 \mathrm{M}$ ethylenediamine (pH8.5) to reduce nonspecific electrostatic interactions. Approximately 30RU (determined for each oligonucleotide using the $R_{\max }$ equation (BIAcore)) of each annealed biotinylated oligonucleotide pair was immobilized to the neutravidin. Experimental conditions were optimized to avoid non-specific binding of the analyte (HSF-1) to the chip surface. The surface of the chip was blocked with multiple injections of biotin $(7 \mathrm{~min}$ at $5 \mu / / \mathrm{min}$ ) and the selected running buffer (10 mM HEPES (pH 7.4), $150 \mathrm{mM} \mathrm{NaCl}$, $3.4 \mathrm{mM}$ EDTA, $0.005 \%$ Tween $20,5 \mathrm{mg} / \mathrm{ml}$ carboxylated dextran) was applied at a flow rate of $20 \mu / \mathrm{min}$. The sensor chip was regenerated, when necessary, by injections of $2.5 \mathrm{M} \mathrm{NaCl}$. Binding kinetics were derived from sensorgrams after subtraction of baselin responses using BIA evaluation software. Dissociation rate constants were determined with the two state reaction (conformational change) model. In this model $A+B$ forms the complex $A B$, which then forms the more stable complex $\mathrm{AB}^{*}$, the rate constants $k_{\mathrm{a} 1}$ and $k_{\mathrm{d} 1}$ represent the formation and dissociation of the complex $\mathrm{AB}$ and $k_{\mathrm{a} 2}$ and $k_{\mathrm{d} 2}$ represent the transition from $\mathrm{AB}$ to $\mathrm{AB}^{*}$. The apparent affinity constant $\left(K_{\mathrm{D}}\right)$ is given by $\left(k_{\mathrm{a} 1} / k_{\mathrm{d} 1}\right)^{*}\left(1+k_{\mathrm{a} 2} / k_{\mathrm{d} 2}\right)$. The validity of using this model was confirmed by running a linked reactions test in which the analyte was injected at a high concentration that reached equilibrium $(500 \mathrm{nM})$ over the ligand surface with a short $(1 \mathrm{~min})$ and a long contact time $(5 \mathrm{~min})$. For each ligand, the dissociation phase for the longer injection was slower than that for the short injection indicating that the binding events are linked (data not shown).

\section{Conflict of interest}

The authors declare no conflict of interest.
Acknowledgements. We thank Dr. Douglas Green for his intellectual input and support of this project. We are also grateful to Drs. Henning Walczak and Shailaja Kasibhatla for their helpful comments. These studies were supported by the National Institutes of Health grant R01GM066914 (to HMB) and the Medical Research Council (MJP).

1. Baler R, Dahl G, Voellmy R. Activation of human heat shock genes is accompanied by oligomerization, modification, and rapid translocation of heat shock transcription factor HSF1. Mol Cell Biol 1993; 13: 2486-2496.

2. Rabindran SK, Haroun RI, Clos J, Wisniewski J, Wu C. Regulation of heat shock factor trimer formation: role of a conserved leucine zipper. Science 1993; 259: 230-234

3. Sarge KD, Murphy SP, Morimoto RI. Activation of heat shock gene transcription by heat shock factor 1 involves oligomerization, acquisition of DNA-binding activity and nuclear localization and can occur in the absence of stress. Mol Cell Biol 1993; 13: 1392-1407.

4. Amin J, Ananthan J, Voellmy R. Key features of heat shock regulatory elements. Mol Cell Biol 1988; 8: 3761-3769.

5. Xiao H, Perisic $\mathrm{O}$, Lis JT. Cooperative binding of drosophila heat shock factor to arrays of a conserved 5bp unit. Cell 1991; 64: 585-593.

6. Wang $\mathrm{Y}$, Morgan WD. Cooperative interaction of human HSF1 heat shock transcription factor with promoter DNA. Nucleic Acids Res 1994; 22: 3113-3118.

7. Kroeger PE, Morimoto RI. Selection of new HSF1 and HSF2 DNA-binding sites reveals difference in trimer cooperativity. Mol Cell Biol 1994; 14: 7592-7603.

8. Hanson DF. Fever, temperature, and the immune response. Ann N Y Acad Sci 1997; 813: 453-464.

9. Cristau B, Schafer $\mathrm{PH}$, Pierce SK. Heat shock enhances antigen processing and accelerates the formation of compact class II alpha beta dimers. J Immunol 1994; 152: 1546-1556.

10. Basu S, Srivastava PK. Fever-like temperature induces maturation of dendritic cells through induction of hsp90. Int Immunol 2003; 15: 1053-1061.

11. Jiang Q, Cross AS, Singh IS, Chen TT, Viscardi RM, Hasday JD. Febrile core temperature is essential for optimal host defense in bacterial peritonitis. Infect Immun 2000; 68: $1265-1270$.

12. Huang $\mathrm{YH}$, Haegerstrand $\mathrm{A}$, Frostegard $\mathrm{J}$. Effects of in vitro hyperthermia on proliferative responses and lymphocyte activity. Clin Exp Immunol 1996; 103: 61-66.

13. Jiang $Q$, Detolla L, Singh IS, Gatdula L, Fitzgerald B, van Rooijen N et al. Exposure to febrile temperature upregulates expression of pyrogenic cytokines in endotoxin-challenged mice. Am J Physiol 1999; 276: R1653-R1660.

14. Singh IS, He J-R, Calderwood S, Hasday JD. A high affinity HSF-1 binding site in the $5^{\prime}$-untranslated region of murine tumor necrosis factor- $\alpha$ gene is a transcriptional repressor. J Biol Chem 2002; 277: 4981-4988.

15. Cahill $C$, Waterman WR, Xie $Y$, Auron PE, Calderwood SK. Transcriptional repression of the prointerleukin B gene by heat shock factor 1. J Biol Chem 1996; 271: 24874-24879.

16. Inouye S, Izu H, Takaki E, Suzuki H, Shirai M, Yokota $Y$ et al. Impaired IgG production in mice deficient for heat shock transcription factor 1. J Biol Chem 2004; 279: 38701-38709.

17. Gothard LQ, Ruffner ME, Woodward JG, Park-Sarge OK, Sarge KD. Lowered temperature set point for activation of the cellular stress response in T-lymphocytes. J Biol Chem 2003; 278: 9322-9326.

18. Brunner T, Mogil RJ, LaFace D, Yoo NJ, Mahboubi A, Echeverri F et al. Cell-autonomous Fas (CD95)/Fas-ligand interaction mediates activation-induced apoptosis in T-cell hybridomas. Nature 1995; 373: 441-444.

19. Ju ST, Panka DJ, Cui H, Ettinger R, el-Khatib M, Sherr DH et al. Fas(CD95)/FasL interactions required for programmed cell death after T-cell activation. Nature 1995; 373 : 444-448.

20. Dhein J, Walczak H, Baumler C, Debatin KM, Krammer PH. Autocrine T-cell suicide mediated by APO-1/(Fas/CD95). Nature 1995; 373: 438-441.

21. Kasibhatla S, Brunner T, Genestier L, Echeverri F, Mahboubi A, Green DR. DNA damaging agents induce expression of Fas ligand and subsequent apoptosis in T lymphocytes via the activation of NF-kappa B and AP-1. Mol Cell 1998; 1: 543-551.

22. Cippitelli M, Fionda C, Di Bona D, Piccoli M, Frati L, Santoni A. Hyperthermia enhances CD95-ligand gene expression in T lymphocytes. J Immunol 2005; 174: 223-232.

23. Tran SE, Meinander A, Holmstrom TH, Rivero-Muller A, Heiskanen KM, Linnau EK et al. Heat stress downregulates FLIP and sensitizes cells to Fas receptor-mediated apoptosis. Cell Death Differ 2003; 10: 1137-1147.

24. Xia X, Voellmy R and Spector NL Sensitization of tumor cells to Fas killing through overexpression of heat-shock transcription factor 1. J Cell Physiol 2000; 183: 425-431.

25. Reap EA, Roof $K$, Maynor K, Borrero M, Booker J, Cohen PL. Radiation and stressinduced apoptosis: a role for Fas/Fas ligand interactions. Proc Natl Acad Sci USA 1997; 94: 5750-5755.

26. Latinis KM, Norian LA, Eliason SL, Koretzky GA. Two NFAT transcription factor binding sites participate in the regulation of CD95 (Fas) ligand expression in activated human T cells. J Biol Chem 1997; 272: 31427-31434.

27. Abravaya K, Phillips B, Morimoto RI. Attenuation of the heat shock response in HeLa cells is mediated by the release of bound heat shock transcription factor and is 
HSF-1 regulates FasL L Bouchier-Hayes et al

1046

modulated by changes in growth and in heat shock temperatures. Genes Dev 1991; $\mathbf{5}$ : 2117-2127.

28. Bonfoco E, Stuart PM, Brunner T, Lin T, Griffith TS, Gao Y et al. Inducible nonlymphoid expression of Fas ligand is responsible for superantigen-induced peripheral deletion of T cells. Immunity 1998; 9: 711-720.

29. Renno T, Hahne M, Tschopp J, MacDonald HR. Peripheral T cells undergoing superantigen-induced apoptosis in vivo express B220 and upregulate Fas and Fas ligand. J Exp Med 1996; 183: 431-437.

30. Xiao X, Zuo X, Davis AA, McMillan DR, Curry BB, Richardson JA et al. HSF1 is required for extra-embryonic development, postnatal growth and protection during inflammatory responses in mice. EMBO J 1999; 18: 5943-5952.
31. Xie Y, Chen C, Stevenson MA, Auron PE, Calderwood SK. Heat shock factor 1 represses transcription of the IL-1beta gene through physical interaction with the nuclear factor of interleukin 6. J Biol Chem 2002; 277: 11802-11810.

32. Schett G, Steiner CW, Groger M, Winkler S, Graninger W, Smolen J et al. Activation of Fas inhibits heat-induced activation of HSF1 and up-regulation of hsp70. FASEB J 1999; 13: 833-842.

33. Schett G, Steiner CW, Xu Q, Smolen JS, Steiner G. TNFalpha mediates susceptibility to heat-induced apoptosis by protein phosphatase-mediated inhibition of the HSF1/hsp70 stress response. Cell Death Differ 2003; 10: 1126-1136.

34. Amin J, Fernandez M, Ananthan J, Lis JT, Voellmy R. Cooperative binding of heat shock transcription factor to the Hsp70 promoter in vivo and in vitro. J Biol Chem 1994; 269: 4804-4811. 